\title{
RNA-based Therapy for Osteogenesis
}

Pinpin Wang ${ }^{1}$, Federico Perche ${ }^{1}$, Delphine Logeart-Avramoglou ${ }^{2}$, Chantal Pichon ${ }^{1, *}$

1: Centre de Biophysique Moléculaire UPR4301 CNRS Rue Charles Sadron Orléans Cedex 02, France

2: Laboratory of Osteoarticular Biology, Bioengineering and Bioimaging UMR CNRS 7052 INSERM U1271, 10, Avenue de Verdun 75010 Paris, France

* Correspondence: pichon@cnrs.fr

\section{Abstract (less than 200 words)}

Nucleic acid-based therapy has shown great promise in accelerating bone regeneration as well as other diseases. Nucleic acids used in gene therapy mainly are either plasmid DNA (pDNA) or RNAs. Although pDNA therapy has been extensively studied for decades with encouraging preclinical and clinical results, side effects and low efficiency associated with nuclear trafficking are hard to bypass. Unlike pDNA, RNAs (mRNA, siRNA, miRNA) exert their function in the cytoplasm thereby being more efficient in hard-totransfect cells such as primary osteoblasts. RNA interference-based gene silencing represents a negative regulation which knockdown the expression of antagonists that impair osteogenesis process. In contrary, mRNA therapy for osteogenesis represents a positive regulation which delivers mRNA encoding growth factors to accelerate bone regeneration. This review presents a comprehensive summary of the mRNA and siRNA-based therapies and the targets for bone regeneration in case of bone defect and osteoporosis. Keywords: osteogenesis, gene therapy, RNA interference, mRNA, protein replacement, osteoporosis

\section{Contents}

\section{Introduction}

Bone tissue has a self-healing capacity which is overwhelmed during traumatic events and bone pathologies- A constant homeostatic balance between bone formation by osteoblasts and bone resorption by osteoclasts is essential for bone tissue to restore fatigue microdamage and maintain bone mass and structure (Rodan and Martin 2000). However, imbalances are associated with pathological or traumatic events. For instance, during some pathologies such as osteoporosis and osteonecrosis, osteoclasts are more active compared to osteoblasts resulting in low bone mass, poor bone strength, and micro-architectural deterioration of bone tissue ((Roush 2011); (Genant, Cooper et al. 1999)). This imbalance increases the risk of bone fracture and subsequently delays bone healing, even leading to nonunion fractures (5-10\% of cases) [(Egermann, Schneider et al. 2005)]. The occurrence of critical-sized 
defects following for instance either traumas or resection of osteosarcomas are additional challenges to the self-healing capacity of bone[(Dimitriou, Tsiridis et al. 2005)].

Osteoporosis- and bone fractures are becoming a major health and economic burden with a progressively aging population. In the European Union, the estimated osteoporotic population was 27.5 million (22 million women and 5.5 million men) in 2010. The cost of osteoporosis-related incidents and osteoporosisrelated fractures was estimated at 37 billion Euro in 2010, which is predicted to increase by $25 \%$ in 2025 (Svedbom, Hernlund et al. 2013).

Clinically, to reverse the loss of bone mass, there are two major pharmacological approaches based on either: 1) anabolic agents such as parathyroid hormone (PTH) to stimulate bone formation; or 2) antiresorptive agents such as bisphosphonate, estrogens, and selective estrogen receptor modulators to prevent bone resorption (NIH Consensus Development Panel on Osteoporosis Prevention and Therapy 2001). However long-term administration of anabolic agents or antiresorptive agents is accompanied by adverse effects. For example, bisphosphonate-based therapy has been associated with jaw osteonecrosis and atypical fractures in long bone [(Schilcher, Michaelsson et al. 2011); (Hollick and Reid 2011)]. To restore bone defects, although the success rate has been significantly improved with the development of sophisticated surgical procedures, e.g. Ilizarov apparatus [(Robert Rozbruch, Weitzman et al. 2006)], Masquelet technique [(Giannoudis, Faour et al. 2011)], autografts still represent the gold standard treatment to treat massive bone loss [(Goldberg and Stevenson 1987); (Giannoudis, Faour et al. 2011)]. This last decade, it is admitted that there is a need to identify novel therapeutic strategies to enhance bone formation without side effects. Romosozumab, a monoclonal antibody targetting sclerostin, was developed as an anabolic and antiresorption drug to treat osteoporosis (Padhi, Jang et al. 2011); (McClung, Grauer et al. 2014); (Cosman, Crittenden et al. 2016). Sclerostin is a negative regulator of bone formation by inhibiting Wnt/ $\beta$-catenin pathway and positive regulator of bone resorption by activating RANK/RANKL pathway (Suen and Qin 2016). However, despite promising results in a recently finished phase three trial, some serious adverse events have been reported such as hyperostosis and cardiovascular events (Cosman, Crittenden et al. 2016).

To repair bone defect, bone tissue engineering represents an interesting therapeutic alternative to bone grafts. Bioengineereed constructs containing a biocompatible scaffold combined with osteogenic cells and/or recombinant osteogenic proteins are increasingly being used as bone graft substitutes[(Amini, Laurencin et al. 2012)]. Although promising results showed bone reparation in clinical studies, many crucial hurdles remain such as side effects related to the supraphysiological dose of implanted osteogenic proteins [(Shimer, Oner et al. 2009)]. 
Gene therapy has been proposed for bone regeneration many years ago. The goal of this approach has been to either sustain or modulate the expression of therapeutic proteins. In vivo and ex vivo strategies have been performed mainly using viral vectors. The pDNA-based gene therapy for osteogenesis will not be covered in the present review, as it has been the focus of recent excellent published reviews [(Evans and Huard 2015);(Im 2013)].

Combining RNAs encoding osteogenic factors, complexed within vectors, in scaffolds in the presence or absence of osteogenic cells is among the most advanced gene therapy ?? solutions for bone healing. The scaffolds can be loaded with either messenger RNA (mRNA), mimics of endogenous microRNA (miRNA), or siRNA to deplete negative regulators of bone formation (Elangovan, Khorsand et al. 2015); (Khorsand, Elangovan et al. 2017); (Takayama, Suzuki et al. 2009). In addition to local release from the scaffold, RNAs can be routed to the bone damaged area using a targeted delivery system, Additional to the local release, RNAs can be systemically administered to target the whole skeleton (Zhang, Wei et al. 2015); (Sun, Ye et al. 2016). In this review, we will discuss the progress of mRNA and siRNA-based gene therapy for the treatment of either bone defects or loss bone mass. But to appreciate the goals of the various strategies, it is needed to give insights on how the bone homeostasis is maintained and what types of molecules are involved during bone regeneration.

\section{Signaling pathways involved in bone homeostasis}

Osteoblasts and osteoclasts are the two major cells involved in bone remodeling or bone defect-healing process. Their recruitment, proliferation, differentiation, activity and survival are tightly regulated by dozens of autocrine and paracrine factors through multiple signaling pathways such as Bone Morphogenetic Proteins (BMPs)/ runt-related transcription factor 2 (Runx2) (Hankenson, Gagne et al. 2015); (Phimphilai, Zhao et al. 2006), Wnt/ß-catenin (Fischer, Boland et al. 2002); (Rawadi, Vayssiere et al. 2003), and receptor activator of nucleic factor-KB (RANK)/ RANK ligand (RANKL) pathways (Wada, Nakashima et al. 2006); (Zhuang, Yoshizawa-Smith et al. 2018). [Fig. 1.]

Bone formation is generated by osteoblasts that promote bone matrix deposition and mineralization. Osteoblasts originate from mesenchymal stem cells (MSCs) that commit and differentiate under the control of various stimuli that influence osteogenesis. One of the key molecular switches in the commitment of mesenchymal progenitors to osteoblast lineage is the transcription factor $\mathrm{cbfa} / \mathrm{run} \times 2$, which has multiple upstream regulators and a wide variety of targets ${ }^{1}$. The Wnt and BMP signaling

${ }^{1}$ Doi: 10.12659/MSMBR.901142 
pathways are the major regulatory pathways involved in the regulation of Runx2. BMPs are cytokine members of the TGF- $\beta$ family that are especially important for postnatal ossification. Among them BMP2, 7 and 9 have been incorporated in bone graft substitutes as recombinant proteins or mRNA (refs). (Hankenson, Gagne et al. 2015). BMP signaling is initiated by the ligand binding to type I and type II BMP receptors which are serine/threonine kinase receptors complexing into transmembrane heterodimer. Upon binding of BMPs to their receptors, the activated receptors initiate two intracellular transduction pathways: the canonical Smad pathway and non-canonical mitogen-activated protein kinase (MAPK) pathway. In canonical pathway, activated receptor recruit and phosphorylate Smad 1/5/8, which are translocated to the nucleus associated with Smad 4. The Smads complex together with Runx2 activates the expression of downstream osteogenic genes such as alkaline phosphatase (ALP), osteocalcin (OCN), osteopontin (OPN) (Chen, Deng et al. 2012). The MAPK pathway is Smad independent and includes the activation of extracellular signal-regulated kinase 1/2 (ERK1/2), p38, and c-Jun NH2-terminal kinase (JNK1/2) resulting in Runx2 expression upregulation (Huang, Yuan et al. 2014).

The BMP/Smad signalling cascade is tightly regulated by both intracellular (such as Smurf proteins) and extracellular processes. A family of secreted antagonists that negatively regulated the BMP/Smad signaling pathway includes Noggin [(Smith and Harland 1992)], Gremlin [(Hsu, Economides et al. 1998); (Pearce, Penny et al. 1999)], Chordin [(Piccolo, Sasai et al. 1996)], crossveinless, USAG-1 and follistatin. Coexpressed with BMP-2, -4 , and -7 , the Noggin, Gremlin, and Chordin antagonists play key roles during development and skeletogenesis [(Zimmerman, De Jesus-Escobar et al. 1996); (Merino, Rodriguez-Leon et al. 1999); (Scott, Steiglitz et al. 2000); (Fisher and Halpern 1999)]. After secretion, these antagonists physically sequester BMPs, preventing ligand-receptor interactions.

Wnt/ $\beta$-catenin signaling is another well-defined signaling pathway that promotes osteoblastic differentiation and activity. Wht proteins constitute a family of secreted cysteine-rich glycosylated proteins. Activation of $\mathrm{Wnt} / \beta$-catenin signaling pathway initiates from binding of the $\mathrm{Wnt}$ ligands with the complex of the 7-transmembrane domain spanning frizzled receptor and low-density lipoprotein receptor-related protein 5 and 6 (LRP5/6) coreceptors. Activation of the Wnt receptor complex

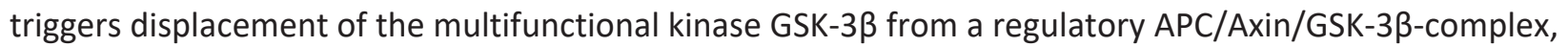
resulting in $\beta$-catenin stabilization and accumulation. The $\beta$-catenin translocates to the nucleus regulating osteogenic genes expression (Krishnan, Bryant et al. 2006). Wnt signaling also reduces apoptosis of osteoblasts and osteocytes through mechanisms involvement of $\beta$-catenin and activation of PI3K/Akt (You, Saims et al. 2002); (Longo, Kennell et al. 2002). 
Several antagonists are involved in Wnt/ $\beta$-catenin signaling regulation. Among them, Dickkopf families (DKK1/2/4) bind to LRP5/6 complex leading to the LRP internalization and degradation (Mao, Wu et al. 2002). Also, the interaction of Wnts and frizzled receptors is inhibited by frizzled-related protein family (sFRP1/2/3) which sequester Wnts (Krishnan, Bryant et al. 2006).

Bone resorption is mediated by osteoclasts which are giant multinucleated cells derived from monocytes/macrophages. Osteoclasts resorb the bone tissue by dissolution of the inorganic phase through acidification of the isolated extracellular microenvironment followed by secretion of proteolytic enzymes. The osteoclast differentiation is locally regulated by RANK/RANKL signaling under the presence of macrophage colony-stimulating factor (M-SCF) (Wada, Nakashima et al. 2006). RANKL, a TNF-family molecule, either expressed on the surface of osteoblastic lineages or secreted from stromal or immune cells, interacts with RANK receptor in osteoclastic lineages. The RANK signaling transduction pathway is regulated by the adaptor proteins of TNF receptor-associated factor 1, 2, 3, 5 and 6 (TRAF 1, 2, 3, 5, 6) within which TRAD 6 is critical for RANK signaling (Koide, Kinugawa et al. 2010). The TRAFs binds to RANK and transmits the RANK signal to downstream targets including nuclear factor-kappa B (NF-KB) pathway and MAPK pathway resulting in osteoclastic differentiation of macrophages cells, activation of bone resorption, and survival of osteoclasts. For example, ERKs and JNKs stimulate transcription factor Activating Protein-1, a dimer composed of c-Fos and c-Jun protein, together with activated NF-KB regulate the expression of nuclear factor of activated T cells c1 (NFATc1, also called NFAT2) leading to enhanced expression of osteoclastogenic genes. Proto-oncogene tyrosine-protein kinase Src (c-SRC) mediates RANK induced activation of the phosphatidylinositol 3-kinase (PI3K)/Akt signaling through binding to TRAF6 for anti-apoptosis (Nakashima, Kobayashi et al. 2000). Osteoblasts also secrete a RANKL decoy receptorosteoprotegerin (OPG) that competitively binds RANKL and, thus, inhibits osteoclast differentiation and survival (Hofbauer and Heufelder 2001); (Maxhimer, Bradley et al. 2015).

RANKL induced-osteoclastogeneis stimulates semaphorn 4d (sema4d) expression from osteoclasts which, in turn, regulates osteoblasts activity (Negishi-Koga, Shinohara et al. 2011). Sema4d is originally expressed as a transmembrane protein then proteolytically cleaved into a soluble form (Suzuki, Kumanogoh et al. 2008). Binding of Sema4d to Plexin-B1, the Sema4d transmembrane receptor in osteoblast, inhibits Akt and Erk phosphorylation resulting in reduction of osteoblast mediated bone-formation.

The unraveling of the signaling pathways and identification of the regulators involved in bone formation and resorption enable to rationally design targeting therapeutics. 


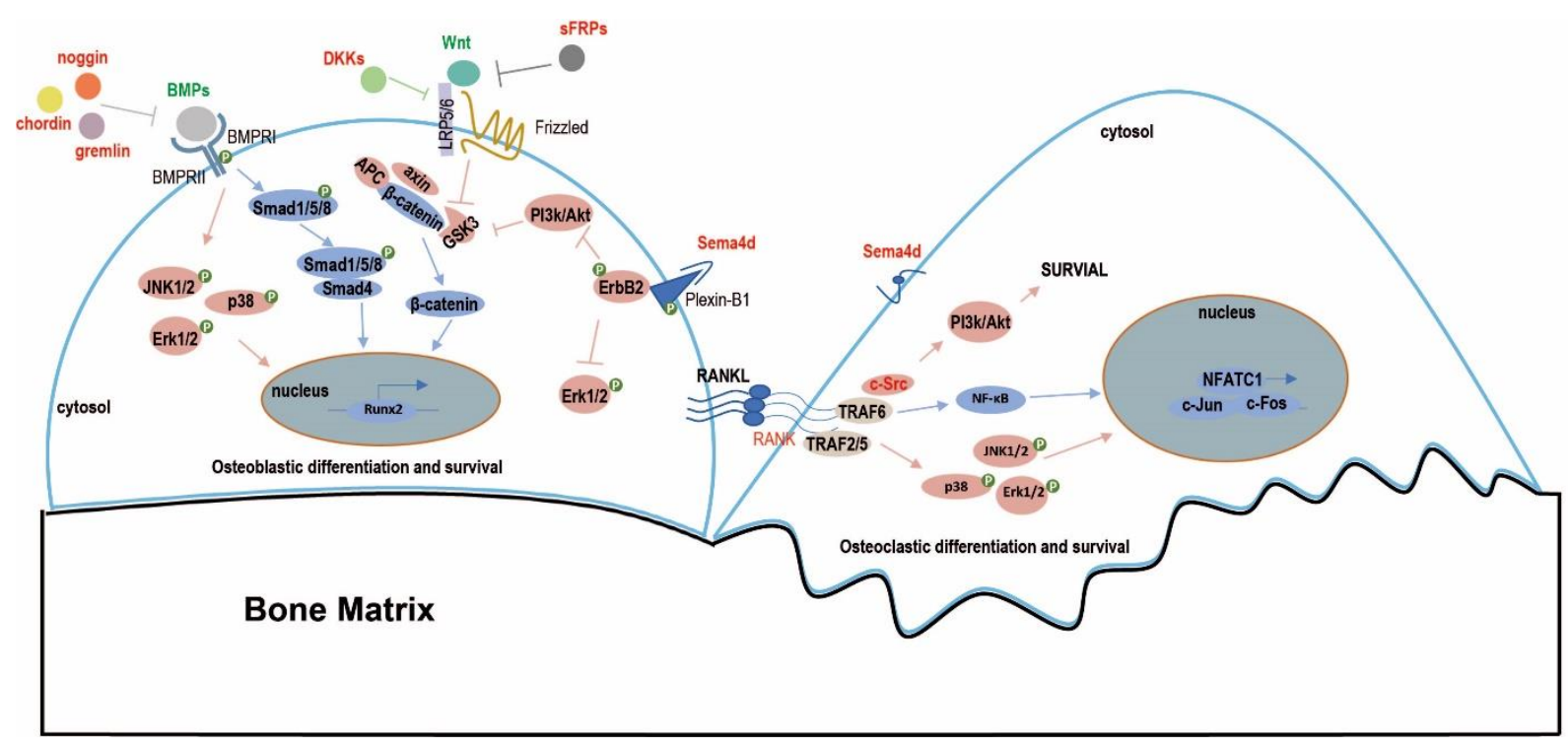

Fig. 1. Selective signaling pathways involved in bone homeostasis. During osteogenesis, BMPs and Wnts induce MSCs to differentiate into osteoblasts, which can be inhibited by extracellular antagonists such as noggin, chordin, gremlin, DKKs, and sFRPs. In the aspect of osteoclastogenesis, hematopoietic cells differentiate into osteoclasts under RANKL stimulation. The osteogenesis and osteoclastogenesis are mutually modulated. Osteoblastic lineages secreted RANKL increases osteoclastic generation and activity. The Sema4d expressed from osteoclasts inhibits osteoblasts activity. On the other hand, osteoclasts digest bone matrix resulting in osteogenic factors release.

\section{RNAi-based therapeutics for osteogenesis}

Compared with conventional pharmalocogical inhibitors, siRNA offer several advantages such as high specificity and facile synthesis (Ozcan, Ozpolat et al. 2015). siRNA can be designed to target a specific gene which is particularly useful to alter signaling pathways [(Miller, Xia et al. 2003)], even proteins inaccessible to conventional drugs [(Filleur, Courtin et al. 2003); (Dorn, Patel et al. 2004)].

In the following section, we focus on the therapeutic approach using siRNA mediated gene silencing to accelerate osteogenesis

\section{1 siRNA mechanism of action}

The RNA interference (RNAi) is a conserved mechanism regulating endogenous gene expression and defending against intracellular pathogens such as viruses [(Agrawal, Dasaradhi et al. 2003)]. The term of RNAi was coined after the discovery that the injected dsRNA lead to specific silencing of genes highly homologous in sequence to the injected dsRNA in Caenorhabditis elegans [(Fire 1999)]. Soon after, Elbashir and colleagues revealed RNAi in mammalian cells [(Elbashir, Harborth et al. 2001)]. 
miRNAs are conserved small non-coding dsRNAs transcribed by genomes that exert RNAi functions through silencing the target mRNAs [(Hannon 2002)]. siRNAs are synthetic dsRNAs designed to silence a specific gene, which has 21-23 nucleotides with 3' 2-nucleotides overhangs and 5' phosphate groups [(Elbashir, Lendeckel et al. 2001)]. The siRNAs can be exogenously introduced into cells in final short form or long dsRNA form which cleaved by Dicer, an RNase III-like enzyme, in cytoplasm to generate functional siRNAs. Interacting with AGO2-RISC enzyme complex, the sense strand of the siRNA is cleaved, and the anti-sense remains associated with the complex. The anti-sense guides the RISC complex binds to the targeting mRNA with full complementarity which then cleaved by AGO2. Fig. 2 exhibits the gene silencing process mediated by siRNA.

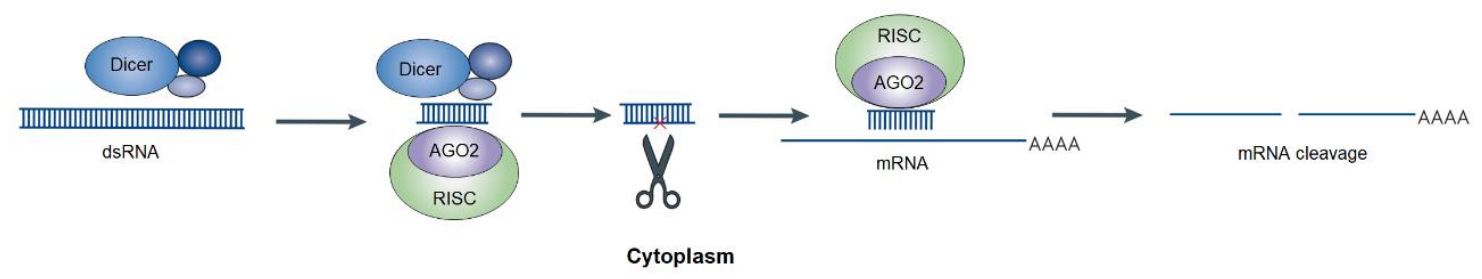

Fig. 2. Schematic mechanism of siRNA mediated RNA interfence in mammalian cells. In cytoplasm, the Dicer enzyme cleaves long double-stranded RNA (dsRNA) to form active siRNA. The siRNA interactes with Argonaute 2 (AGO2) and the RNAi-induced silencing complex (RISC) leading to cleavage of the sense strand by AGO2. The target mRNA with complementary sequence to the antisese strand is recognized and cleaved. Reproduced from (de Fougerolles, Vornlocher et al. 2007) with permission.

\subsubsection{Silencing BMPs antagonists:}

a) noggin siRNA

Among the BMP antagonists, noggin is identified to be the most closely involved in the osteoinductive process of BMPs [(Smith and Harland 1992); (Abe, Yamamoto et al. 2000)]. Several studies demonstrated that increase noggin expression significantly impairs bone formation both in vitro and in vivo [(Devlin, Du et al. 2003); (Xiao, Gopalakrishnan et al. 2002); (Wu, Li et al. 2003)]. These studies reinforce the crucial role of noggin as a negative regulator of bone formation. Wan and colleagues were the pioneers of this strategy. Retroviral particles encoding noggin siRNA were used for in vitro and in vivo experiments [(Wan, Pomerantz et al. 2007)]. In vitro itroduction of noggin siRNAs into MC3T3-E1 resulted in approximately $90 \%$ noggin transcripts reduction. Noggin elimination increased the Smad1/5 phosphorylation inducing BMP signaling, which results to the increase of calcium deposition. In vivo strategy was based on primary calvarial osteoblasts transduced with noggin siRNA soaked into apatite-coated polylactic-co-glycolic acid 
scaffolds before implantation into a mice calvarial defect. After 2 weeks, the goup of mice implanted with noggin down expressing cells demonstrated around 6-fold more bone content than the vehicle control group. Reducing noggin levels enhances both intracellular and extracellular activities of BMPs, which is of benefit compared to BMPs administration requiring supraphysiological BMP doses, always associates with some side effects (Shimer, Oner et al. 2009). Indeed, noggin expression was upregulated when recombinant BMP-2 was used to stimulate murine $\mathrm{C} 2 \mathrm{C} 12$ myoblasts and mesenchymal stem cells (MSC), which in turn inhibits the osteogenic function of BMP-2. (Takayama, Suzuki et al. 2009); (Chen, Uludag et al. 2012). Studies from Takaoka's group demonstrated that noggin siRNA delivery abrogated rhBMP-2 induced noggin expression, resulting in accelerated osteoblastic differentiation of $\mathrm{C} 2 \mathrm{C} 12$ cells in vitro and ectopic bone formation in vivo compared to rhBMP2 alone [(Takayama, Suzuki et al. 2009); (Manaka, Suzuki et al. 2011)]. Manaka and colleagues used a biodegradable hydrogel made from poly-D, L-lactic acid-p-dioxanonepolyethylene glycol block copolymer (PLA-DX-PEG) for noggin siRNA in vivo delivery. Implant of noggin siRNA and rhBMP2 containing PLA-DX-PEG hydrogel into a mice dorsal muscle pouch successfully inhibited rhBMP2 induced noggin expression compared to hydrogel blend with rhBMP2 and control siRNA. The suppression effect lasts for up to 7 days with the peak occurring at day 2 (Manaka, Suzuki et al. 2011).

The function of noggin silencing to benefit bone regeneration was improved when high efficient vector to deliver noggin siRNA was used (Choi, Cui et al. 2015); (Inada, Tamura et al. 2018). As an example, Cui and colleagues developed a sterosome vector composed of stearylamine (SA) and cholesterol (Chol) for delivering noggin siRNA to enhance the osteogenic differentiation of AMSCs (Cui, Fan et al. 2015). The freshly prepared SA/Chol/siRNA nanoparticles (NPs) exhibited high transfection efficiency (93\%) comparable to commercial vector lipofectamine $2000^{\circledR}(96 \%)$. The value decreased to approximately $60 \%$ after incubating at $37^{\circ} \mathrm{C}$ for 2 weeks, while it was highly reduced to $0.2 \pm 0.1 \%$ for lipofectamine $2000^{\circledR}$ demonstrating that SA/Chol/siRNA NPs has excellent colloidal stability. Cells transfected with $\mathrm{SA} / \mathrm{Chol} /$ noggin siRNA showed more than $45 \%$ noggin expression reduction significantly higher than that obtained using lipofectamine $2000^{\circledR}$ ( $\left.25 \%\right)$. In a mouse calvarial defect model, methacrylated glycol chitosan (MeGC) hydrogel encapsulating AMSCs transfected with SA/Chol/noggin siRNA particles was implanted into the defect site. Defects treated with SA/Chol/noggin siRNA were filled with 20\% regenerated bone tissue which are $\sim 15 \%$ and $\sim 5 \%$ for using lipofectamine $2000 /$ siRNA groups and control siRNA groups, respectively. This example point out the discrepancy that could be obtained between the in vitro and in vivo efficiency. 
b) chordin and gremlin siRNAs

Silencing chordin and gremlin could led as well to enhanced osteogenesis in vitro and in vivo. The study from Kwong et al. firstly demonstrated that delivery of siRNA against chordin accelerates BMSCs osteogenic differentiation (Kwong, Richardson et al. 2008). Comparing the expression of noggin, gremlin, chordin in bone marrow stem cells (BMSCs) isolated from patients with normal fracture healing and those with bone nonunion (BMSCs/N), Wang et al. found that chordin expression was the most upregulated (Wang, Xiao et al. 2018). Silencing chordin in BMSCs/N yielded more expression of osteogenic markers than gremlin and noggin silencing. Based on these observations, the authors defined chordin as the ideal target for inducing BMSc/N osteogenic differentiation. Next, they tested different vehicles, i.e. polyspermine imidazole-4,5-imine (PSI), Polyethyleneimine of varios size ( 800 and $25 \mathrm{kDa}$ ) and spermine, to optimize chordin siRNA delivery. Results of in vitro osteogenic differentiation and in vivo bone regeneration demonstrated that PSI was the most potent vector followed by PEI 25KDa.

Interestingly, transfecting ST-2 stromal cells with gremlin siRNA using siLentFect ${ }^{\circledR}$ significantly enhanced the stimulatory effect of BMP-2 on alkaline phosphatase expression at all BMP-2 doses (0-10nM) tested (Gazzerro, Smerdel-Ramoya et al. 2007). Such enhancement relied on increased Smad1/5/8 phosphorylation. Moreover, gremlin silencing enhanced as well Wnt3a signaling. A recent study showed gremlin knockdown by lipofectamine $2000^{\circledR} /$ gremlin-siRNA enhanced human MSCs osteogenic differentiation [(Hu, Sun et al. 2017)]. To date, no in vivo published studies using gremlin siRNA for bone formation.

\subsubsection{Silencing osteoclasts stimulants and osteoblasts inhibitors}

During osteoporosis, overactivation of osteoclasts results in the decreased bone mass and high-risk bone fracture that dramatically influence the quality of life. Osteoblast-osteoclast communication is mediated by several pairs of ligands and receptors which are potential therapeutical targets to modulate bone regeneration. RANK/RANKL is known to be a critical signaling initiating osteoclast formation and activity. Silencing RANK gene with RANK siRNA successfully inhibited osteoclast differentiation of RAW264.7, a murine-macrophage osteoclast precursor cell line, in vitro (Wang and Grainger 2010); (Wang, Tran et al. 2012); (Ma, Yang et al. 2014); (Sezlev Bilecen, Uludag et al. 2019). Transfecting RAW cells with DharmaFECT4/ RANK-siRNA complexes, Wang and colleagues as pioneers, suppressed osteoclastic RAW cells as well as primary osteoclast precursors differentiation from mouse bone marrow cells. Two transfection strategies were tested for RANK silencing which are one single transfection, and 3 successive transfections performed every other day. Both showed significant reduction of RANK expression and osteoclast formation, especially upon multiple transfections. In the study, osteoclast-mediated bone 
resorption were measured by seeding cells onto bovine bone slices. Results showed that the resorption pit numbers on bone slices were markedly curtailed in the RANK-siRNA treated groups.

Proto-oncogene tyrosine-protein kinase Src (c-Src) is a factor downstream RANK signaling controls bone metabolism by maintenance of osteoclast function [(Boyce, Yoneda et al. 1992); (Lowe, Yoneda et al. 1993)]. Knockdown c-Src in mice showed increased bone formation leading to osteopetrosis [(Frattini, Orchard et al. 2000)]. Zhang et al. injected jetPEI ${ }^{\circledR} /$ Src-siRNA complexes into the proximal femur in a corticosteroid-induced osteoporosis rabbit model [(Zheng, Wang et al. 2016)]. Src siRNA administration reduced Src mRNA level to $\sim 50 \%$ in bone marrow cells of treated rabbits. Micro-computed tomography $(\mu \mathrm{CT})$ analysis revealed that Src siRNA prevented bone loss in metaphyseal trabecular and maintained the bone mineral density similar to normal rabbit, whereas non-Src targeting siRNA groups and vehicle control group showed remarkably lower bone mineral densities.

Semaphorin 4d (Sema4d) is a recently uncovered molecule involved in osteoclast-osteoblast communication (Negishi-Koga, Shinohara et al. 2011). Sema4d secreted from osteoclasts reduced the osteoblastic differentiation of cocultured BMSCs, which was reversed by knockdown Sema4d in osteoclasts by Sema4d siRNA [(Zhang, Wei et al. 2015)]. The negative regulation property to osteoblast activity makes Sema4d a targeting candidate to increase osteogenesis. Intravenously delivery of Sema4d siRNA complexed with a bone targeting polymer, $\mathrm{N}$-(2-hydroxypropyl)methacrylamide (HPMA) copolymers with D-aspartic acid octapeptide (D-Asp8), to murine osteopenia model resulted in improved bone mineral density, bone volume, and trabecular thickness (Zhang, Wei et al. 2015). The Sema4d siRNA particles also worked to reverse periodontal disease induced alveolar bone loss (Zhang, Wei et al. 2014).

Table 1 . Summary of representive studies based on siRNA for in vivo osteogenesis.

\begin{tabular}{|c|c|c|c|c|c|}
\hline antagonist & Target & Vector & In vivo delivery & in vivo model & Ref. \\
\hline \multicolumn{6}{|c|}{ Local delivery } \\
\hline \multirow{2}{*}{ Chordin } & \multirow{4}{*}{ BMP2 } & $\begin{array}{l}\text { PSI; PEI800; } \\
\text { PEI25KDa; } \\
\text { spermine }\end{array}$ & $\begin{array}{l}\text { Matrigel/ } \\
\text { transfected hBMSCs }\end{array}$ & $\begin{array}{l}\text { Mouse tibial } \\
\text { monocortical } \\
\text { defect }\end{array}$ & $\begin{array}{l}\text { (Wang, Xiao et } \\
\text { al. 2018) }\end{array}$ \\
\hline & & $\begin{array}{l}\text { PEI-Et; PEI800; } \\
\text { PEI25KDa }\end{array}$ & $\begin{array}{l}\text { Matrigel/ } \\
\text { transfected hBMSCs }\end{array}$ & $\begin{array}{l}\text { Mouse tibial } \\
\text { monocortical } \\
\text { defect }\end{array}$ & $\begin{array}{l}\text { (Wang, Yuan et } \\
\text { al. 2017) }\end{array}$ \\
\hline \multirow{2}{*}{ Noggin } & & retrovirus & $\begin{array}{l}\text { Apatite coated PLGA } \\
\text { scaffold /calvarial } \\
\text { osteoblasts }\end{array}$ & $\begin{array}{l}\text { Mouse Calvaria } \\
\text { defect }\end{array}$ & $\begin{array}{l}\text { (Wan, } \\
\text { Pomerantz et } \\
\text { al. 2007) }\end{array}$ \\
\hline & & $\begin{array}{l}\text { Lipofectamine } \\
2000^{\bigcirc, R}\end{array}$ & $\begin{array}{l}\text { dorsal muscle } \\
\text { injection followed by } \\
\text { electroporation }\end{array}$ & $\begin{array}{l}\text { Mouse ectopic } \\
\text { bone formation- } \\
\text { dorsal muscle }\end{array}$ & $\begin{array}{l}\text { (Takayama, } \\
\text { Suzuki et al. } \\
\text { 2009) }\end{array}$ \\
\hline
\end{tabular}




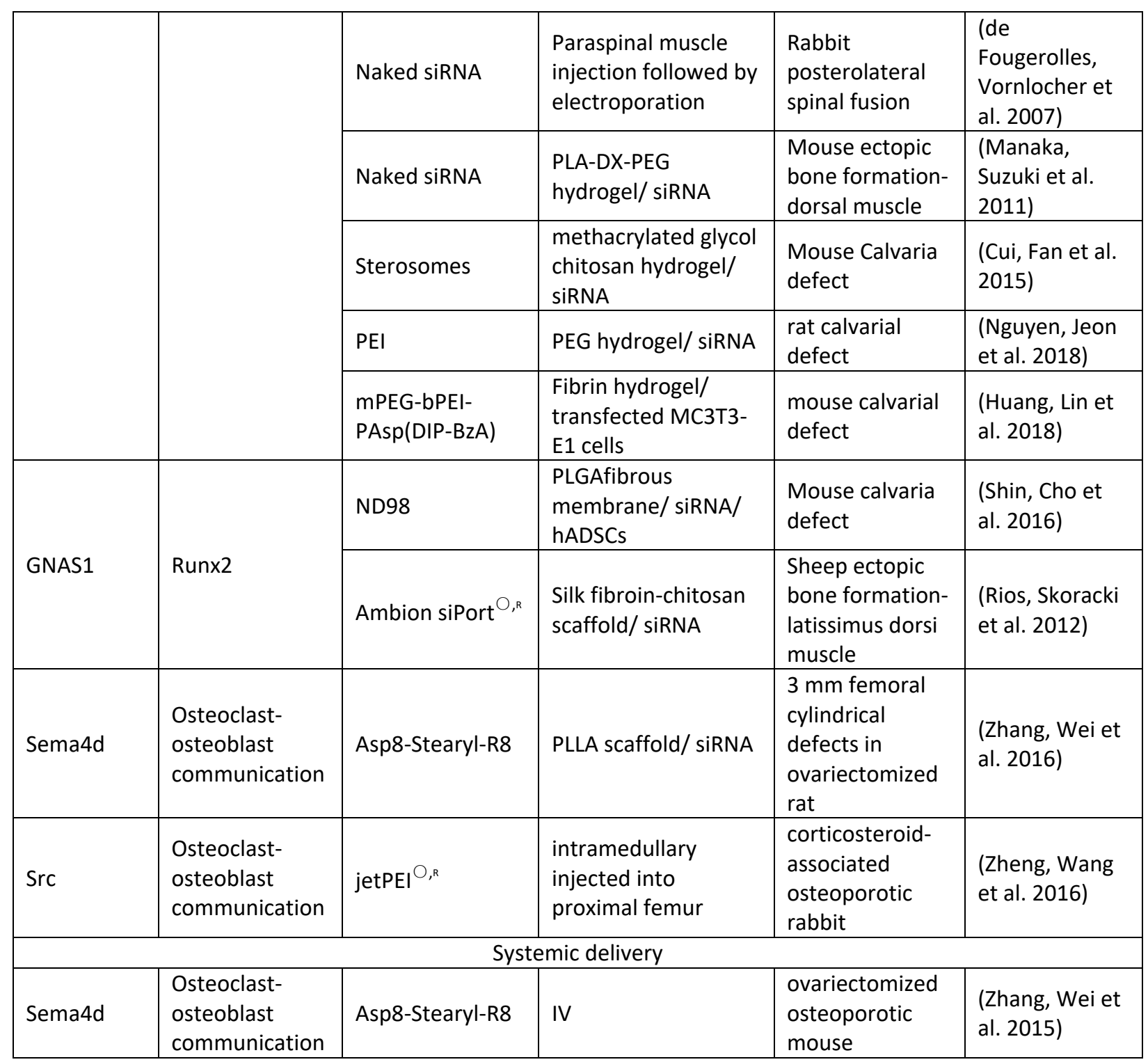

PEI: polyethylenimine; PSI: polyspermine imidazole-4,5-imine; PEI-Et: ethylene bis linked low-molecularweight polyethylenimine; GNAS1: guanine nucleotide-binding protein alpha-stimulating activity polypeptide $\quad 1 ; \quad$ mPEG-bPEI-PAsp(DIP-BzA): monomethoxy-poly(ethylene glycol)-b-branched polyethyleneimine-b-poly( $\mathrm{N}$-( $\mathrm{N}^{\prime}, \mathrm{N}^{\prime}$-diisopropylaminoethyl)-co-benzylamino)aspartamide); PLA-DX-PEG: poly-D,L-lactic acid-p-dioxanonepolyethylene glycol block co-polymer; ND98: five-tailed isomer of triethylenetetramine-laurylaminopropionate with a free internal amine, Cholesterol, and mPEG2000-C14 Glyceride; PLLA: poly-L-lactic acid; Asp8-Stearyl-R8: D-aspartic acid Octapeptide grafted Stearylated octaarginine; IV: intravenous; Sema4d: semaphorin 4d.

\subsection{Challenges and perspectives}

siRNA-based therapeutics hold great promises as they can virtually silencing any genes, which may be inaccessible with conventional small molecules or protein drugs. In August 2018, FDA approved the first 
ever siRNA against transtyrethin mRNA (Patisiran) responsible of hATTR, a life- threatening neurodegenerative rare inherited disease opens a real new type of pharamaceutics ((Adams, Suhr et al. 2017)). Today, many advances in design of siRNA have permitted this this landmark achievement. The first challenge is to design a rational siRNA sequence with high silencing efficiency, without off-target effects and immunogenicity. The off-target occurs when the siRNA has partial complementarity in the seed region with unintended genes. Moreover, siRNAs complementary to different regions of the target mRNA could result to diverse silencing efficiency. Today, there are siRNA design algorithms that can help to predict the silencing efficacy and reduced off-target effect (Chaudhary, Srivastava et al. 2011) (Naito and Ui-Tei 2013). siRNA is also known to induce innate immune system in mammals ((Kariko' et al. 2004a, Sioud and Sørensen 2003). It results in induction of interferon (IFN) and pro-inflammatory cytokines production. Duplexes of siRNA can be sensed by PKR and TLR3/7/8, which can be reduced by chemical modifications, e.g. ribose 2'-OH group modification, locked and unlocked nucleic acids modification, and backbone phosphorothioate modification (Lam, Chow et al. 2015)..

The second challenge is the delivery of siRNA to the target sites in an efficient and safe manner. siRNAs share the same types of non viral delivery systems with other nucleic acids, which are polymer-based vectors, lipid-based vectors, and inorganic vectors. Despite the progress made in improved transfection efficiency and reduced toxicity, delivering therapeutic siRNA for osteogenesis meets unique barrier. For optimal therapeutical effects, bone targeting vectors are needed. Some ligand moieties showed bone targeting ability such as bisphosphonates, oligopeptides (Asp) 8 and (AspSerSer) $)_{6}$, and aptamers which have high affinity to calcium in hydroxyapatite, crystalline hydroxyapatite, amorphous hydroxyapatite, and osteoblast, respectively (Liu 2016). Bone-specific delivery systems were obtained by conjugating those moieties to delivery systems and their use resulted to some promissing results (Zhang, Wei et al. 2016) (Zhang, Wei et al. 2015). Covalent Tetracyclines (TCs), conjugation with poly(lactic-co-glycolic acid) (PLGA) copolymer (TC-PLG1) could be another delivery system alternative (Wang, Liu et al. 2015). TC is an antibiotic agent that has been found to be taken up by bone via its interaction with hydroxyapatite Ca10(PO4)6(OH) ((Perrin 1965)). PLGA is an FDA approved biodegradable polymer that is wildly used to delivery therapeutic molecules including nucleic acids (Wang, Tran et al. 2012). In ovariectomized osteoporosis rat model, TC-PLGA nanoparticles have a tendency to accumulate in bone compared to PLGA alone (Wang, Liu et al. 2015). When loaded with simvastation, TC-PLGA particles were more potent to enhance bone mineral density over PLGA. It could be worthwhile to exploit similar strategy for siRNA. 


\section{3 mRNA-based therapeutic for osteogenesis}

\subsection{Eukaryotic mRNA and in vitro transcription}

mRNAs are the intermediate between the genetic information stored in DNA and proteins. DNA is first transcribed into mRNA in the nucleus before mRNA exports and translation into proteins by the ribosomes in the cytoplasm. All mature eukaryotic mRNA consists of five moieties, which are the 5' methylated guanosine cap $\left(\mathrm{m}^{7} \mathrm{Gp} 3 \mathrm{~N}\right)$, the $5^{\prime}$ and $3^{\prime}$ untranslated region (5'-UTR and $3^{\prime}$-UTR) flank the open reading frame (ORF), and the 50-250 adenosine residues (poly(A) tail) [(Jackson 1993); (Banerjee 1980)]] (Fig. 3). ORF stores protein information in the codon sequence while the rest moieties responsible for regulation of mRNA translocation, translation, and stability. Understanding the mechanisms behind mRNA translation and stability regulation has been useful to guide the design of in vitro transcribed (IVT) mRNA and increase the efficacy of mRNA therapy.

The $5^{\prime} \mathrm{m}^{7} \mathrm{G}$ cap is an evolutionarily conserved modification of eukaryotic mRNA with an $\mathrm{N}^{7}$ methylated guanosine covalent to the first nucleotide of the pre-mRNA via a reversed 5' to 5' triphosphate linkage. Additional to $N^{7}$ methylation in $5^{\prime} m 7 G$ cap $(m 7 G p p N$, Cap 0), in higher eukaryotes, methylation also occurs at the 2'-O position of the +1 ribonucleotide $\left(m^{7} \mathrm{GpppNm}\right.$, Cap 1) and +2 ribonucleotide (m7pppNmNm, Cap 2), respectively [(Wei, Gershowitz et al. 1975);(Langberg and Moss 1981)]. The cap structure and properties were revealed in the 1970s, due to the technical development of purification mRNA based on the poly(A) structure (Edmonds, Vaughan et al. 1971); (Mendecki, Lee et al. 1972). The majority of cellular mRNA translation is initiated in a cap-dependent manner. The cap acts as an anchor for recruiting eukaryotic translation initiation factor 4F complex (elF4F complex), including elF4E, elF4G, and elF4A, which is responsible for the recruitment of $43 \mathrm{~S}$ complex of the small ribosomal subunit and associated translation factors to form the 48 S pre-initiation complex (McCormick and Khaperskyy 2017). mRNA lacks $\mathrm{m}^{7} \mathrm{G}$ cap exhibited at least ten folds protein expression reduction (Horikami, De Ferra et al. 1984); (Lo, Huang et al. 1998). Cap analogs, such as GpppG, $m^{7} G p p p G$ and $m^{7} G p p p G m$, are incorporated into RNAs during IVT (Konarska, Padgett et al. 1984); (Contreras, Cheroutre et al. 1982). However, onethird of the IVT mRNA is improperly capped thus poorly recognized by the translation initiation machinery [(Matsuo, Li et al. 1997); (Cai, Jankowska-Anyszka et al. 1999)]. To address this problem, the Jemielity group developed the anti-reverse cap analog (ARCA) in which the hydroxyl group in C2 or C3 position of the $\mathrm{m}^{7} \mathrm{G}$ is removed or substituted with methoxy group [(Stepinski, Waddell et al. 2001); (Jemielity, Fowler et al. 2003)]. The ARCA-capped mRNA resulting in increased as well as prolonged protein expression [(Mockey, Goncalves et al. 2006); (Zohra, Chowdhury et al. 2007)]. A further improvement in synthetic 
cap analogs has been achieved using sulfur to substitute a nonbridging oxygen in either the $\alpha$, $\beta$, or $\gamma^{-}$ position of the triphosphate. This substitution leads to an inhibition of pyrophosphatase Dcp1p/Dcp2p mediated mRNA decapping degradation (Grudzien-Nogalska, Jemielity et al. 2007). Another option is to replace the triphosphate with tetraphosphate to increase the affinity to translation initiation factor elF4E to the cap analog (Strenkowska, Kowalska et al. 2010).

5' and 3' UTRs play crucial roles in mRNA regulation of translocation (Jansen 2001), translation (van der Velden and Thomas 1999)] and stabilization (Bashirullah, Cooperstock et al. 2001). 5'-UTR regulates mRNA translation efficiency through its structure features, i.e., length, secondary structure, nucleotide sequence (Mignone, Gissi et al. 2002). The best context for translation initiation is when the starting methionine codon (AUG) is in a Kozak sequence context (GCC $\left./{ }_{G} C C A \cup G G\right)$ with a purine at the -3 position and a guanine at the +4 position (Kozak 1987), (Kozak 2005). Yang et al. found that mRNAs with longer 3'-UTR $(>1 \mathrm{~Kb})$ decayed at a significantly faster rate than shorter 3'-UTR (Yang, van Nimwegen et al. 2003). Additionally, the exosome complex destructs transcripts bearing AU-rich motifs (Chen, Gherzi et al. 2001); (Mukherjee, Gao et al. 2002), especially when the AU-rich motif is located in the 3'-UTR (Yang, van Nimwegen et al. 2003).

Poly (A) tail is also essential to improve mRNA intracellular stability and for successful translation initiation. Initiation of translation requires the formation of a pre-initiation complex (PIC) which is Poly(A) tail binds to polyadenylate-binding protein 1 (PABP) then interacts with elF4G leading to mRNA circulation (Gallie 1998). The length of the poly(A) tail is essential for mRNA stability. Eukaryotic mRNA undergoes progressive deadenylation leading to decapping followed by 5'-3' exonucleolytic degradation (Coller and Parker 2004). Transcripts with a short poly(A) tail are shown more vulnerable to decapping (Couttet, Fromont-Racine et al. 1997). In parallel, translation efficient of administered IVT mRNA is positively correlated with poly(A) tail length (Mockey, Goncalves et al. 2006); (Peng, Murray et al. 2008). The poly(A) tail could be either put on the template or added post IVT by enzymatic polyadenylation; the former strategy resulting in less polydisperse mRNA with higher translational activity (Grier, Burleigh et al. 2016). In summary, the IVT mRNA should at least contains a cap structure, a poly(A) tail longer than 12 A residues which is the minimum poly(A) length for PABP binding (Sachs, Davis et al. 1987). For optimal expression and stability, the $5^{\prime}$ and $3^{\prime}$ UTR with designed sequence can be added. 


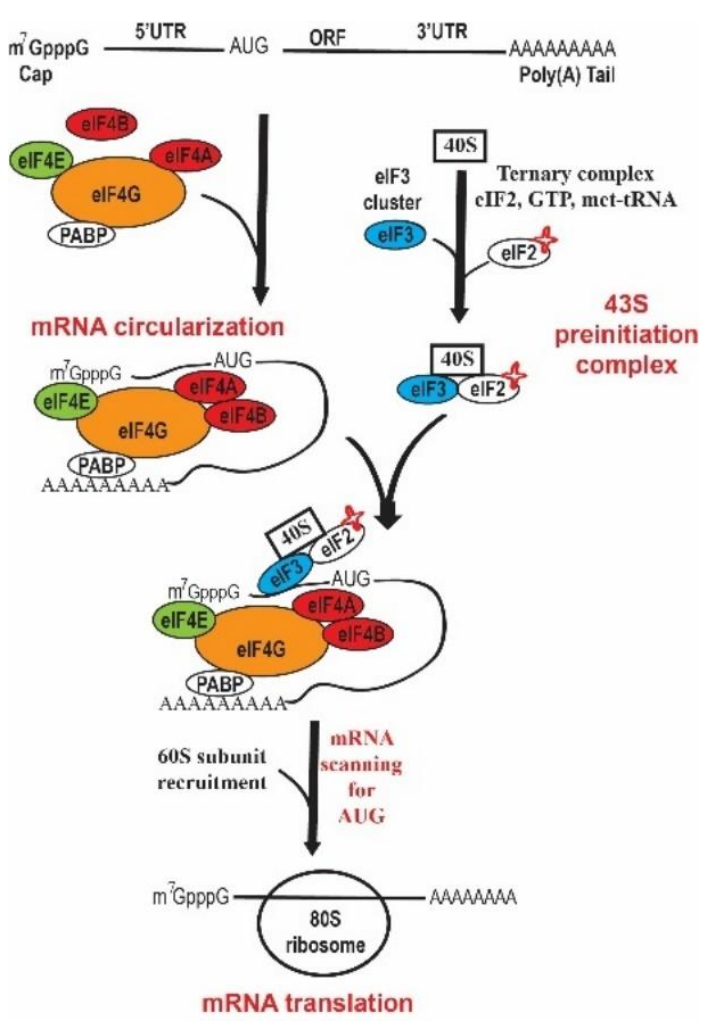

Fig. 3: Eukaryotic mRNA structure and translation initiation. Mature eukaryotic mRNA consists the 5' methylated guanosine cap ( $\left.\mathrm{m}^{7} \mathrm{Gp} 3 \mathrm{~N}\right)$, the $5^{\prime}$ and $3^{\prime}$ untranslated region (5'-UTR and $3^{\prime}$-UTR) flank the

open reading frame (ORF), and the 50-250 adenosine residues (poly(A) tail). During translation, eukaryotic translation initiation factor $4 \mathrm{E}$ (elF4E) binds to the $\mathrm{m}^{7} \mathrm{Gp} 3 \mathrm{~N}$ cap, and polyadenylate-binding protein 1 (PABP1) binds to the $3^{\prime}$ poly(A) tail, followed by recruitment of elF4G and elF4A, leading to mRNA circularization. The translation initiation factor $4 F$ complex (elF4E, elF4G, and elF4A) recruits $43 \mathrm{~S}$ preinitiation complex and associated translation factors to the $5^{\prime}$-UTR. Next, tRNA ${ }^{\text {met }}$ recognizes the initiation codon (AUG), and large ribosome subunit (80S) locks the ORF and starts polypeptide synthesis.

\section{2 mRNA therapy and immunogenicity}

Introducing exogenous mRNA into cells to express protein of interest started three decades ago. In 1989, Malone and colleagues transfected tissue cultured NIH3T3 cells with IVT P. pyralis luciferase mRNA using a synthetic cationic lipid (Malone, Felgner et al. 1989). The following year, Wolff and colleagues first demonstrated the feasibility of IVT mRNA mediated protein expression in vivo by direct injection of naked IVT mRNAs into mouse skeletal muscle [(Wolff, Malone et al. 1990)]. In 1992, arginine vasopressin IVT mRNA was used to treat genetic mutation of vasopressin-induced diabetes insipidus in rat (Jirikowski, 
Sanna et al. 1992). The diabetes insipidus was temporarily reversed for up to 5 days. Since then, extensive studies were focused on mRNA therapy (Tavernier, Andries et al. 2011)(Schlake, Thess et al. 2018). Although mRNA design, synthesis, and delivery methods gained remarkable progress, the use of mRNA has been so far limited to vaccination because of its instability and immunogenicity [(Pascolo 2008); (Schlake, Thess et al. 2018). After internalization, mRNA is mainly accumulated into endosomes, where the IVT mRNAs are recognized by Toll-like receptors (TLRs), specifically TLR3, 7, and 8, located in the endosome membrane [(Kariko, Buckstein et al. 2005); (Alexopoulou, Holt et al. 2001); (Heil, Hemmi et al. 2004)]. Binding of RNA to TLR results in the induction of an antiviral response resulting in RNA degradation and translational shutoff. TLR3 recognizes double-stranded RNA, and TLR7/8 recognize single-stranded RNA. The TLRs stimulation induces type I interferon (INF $\alpha / \beta)$ expression and associated anti-viral responses resulting in IVT mRNA translation suppression and degradation, and even host cell apoptosis [(Kariko, Ni et al. 2004); (Dan, Zheng et al. 2012)]. The comprehensive immune responses induced by IVT mRNA is shown in Figure 4.

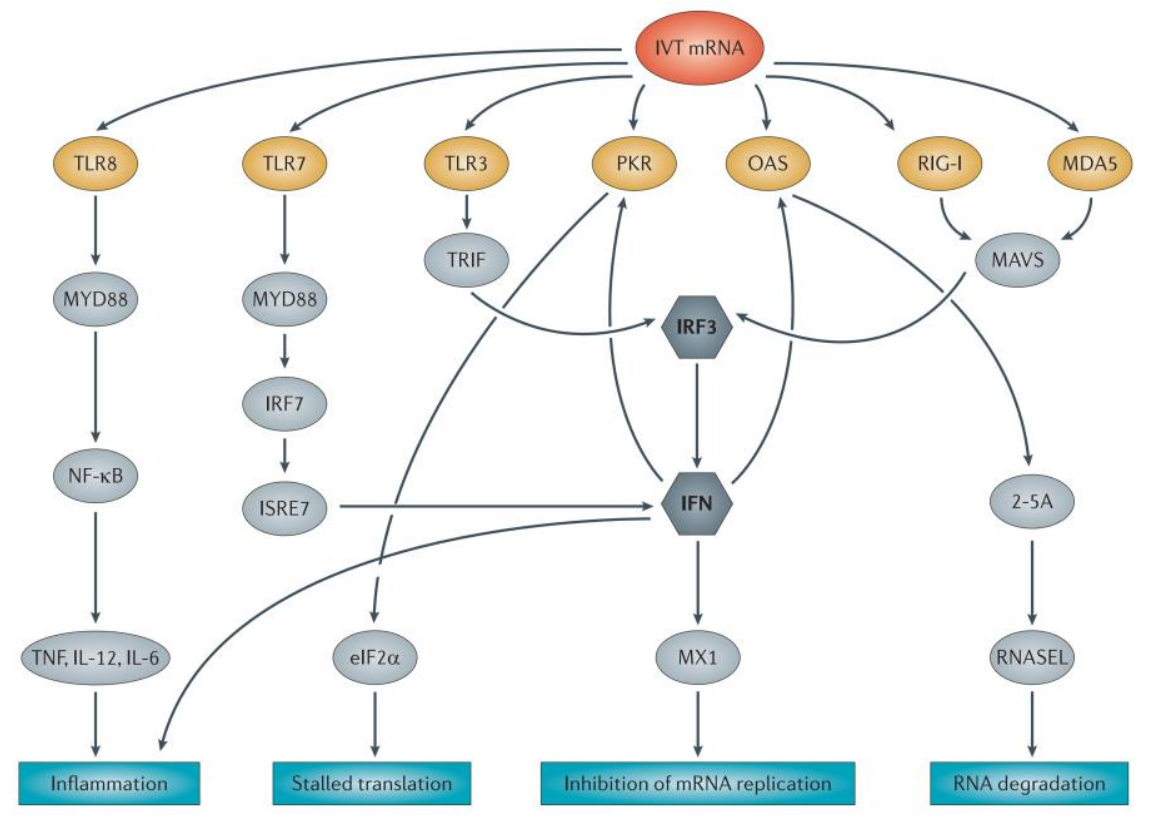

Fig. 4. Immune responses to synthetic mRNA. In vitro transcribed (IVT) mRNA is recognized by various endosomal innate immune receptors (Toll-like receptor 3 (TLR3), TLR7 and TLR8) and cytoplasmic innate immune receptors (protein kinase RNA-activated (PKR), retinoic acid-inducible gene I protein (RIG-I), melanoma differentiation associated protein 5 (MDA5) and 2'-5'-oligoadenylate synthase (OAS)). Signaling through these different pathways results in inflammation associated with type 1 interferon (IFN), tumor necrosis factor (TNF), interleukin-6 (IL-6), IL-12 and the activation of cascades of 
transcriptional programmers. Overall, these create a pro-inflammatory microenvironment poised for inducing specific immune responses. Moreover, downstream effects such as slow-down of translation by eukaryotic translation initiation factor $2 \alpha$ (elF $2 \alpha$ ) phosphorylation, enhanced RNA degradation by ribonuclease L (RNASEL) overexpression and inhibition of replication of self-amplifying mRNA are of relevance for the pharmacokinetics and pharmacodynamics of the IVT mRNA. IRF, interferon regulatory factor; ISRE7, interferon-stimulated response element; MAVS, mitochondrial antiviral signaling protein; MDA5, melanoma differentiation-associated protein 5; MYD88, myeloid differentiation primary response protein 88; MX1, myxovirus (influenza) resistance 1; NF-KB, nuclear factor-KB; TRIF, Toll-IL-1 receptor domain-containing adapter protein inducing IFN $\beta$. Adapted from (Sahin, Kariko et al. 2014) with permission.

In the last 10 years, the discovery that incorporation of naturally modified nucleotides, such as pseudouridine, 5-methylcytidine, N6-methyladenosine, 5-methyluridine, or 2-thiouridine, suppressed IVT mRNA induced TLR3/7/8 activation in human DCs revitalized mRNA-based therapies [(Kariko, Buckstein et al. 2005); (Freund, Eigenbrod et al. 2019). Further, Kariko and colleagues compared the influence of each modified nucleotides in mRNA translation [(Kariko, Muramatsu et al. 2008)]. Interestingly, although pseudouridine is primarily found in tRNA, rRNA, and small nuclear RNA (Anderson, Muramatsu et al. 2010), incorporation of pseudouridine into mRNA showed the highest translation enhancement in vitro, because pseudouridine incorporation changed the mRNA structure motifs which can active RNA-dependent protein kinase (PKR) leading to inhibition of translation initiation by elF2 $\alpha$ phosphorylation [(Zheng and Bevilacqua 2004)]. In addition to the nucleotides mentioned above, other modified nucleotides also exhibited the ability to increase mRNA translation and stability (Li, Luo et al. 2016). Svitkin and colleagues showed N1-methyl-pseudouridine modified luciferase mRNA yield 7.4-fold luciferase expression compared to non-modified mRNA, which was higher than the 5-methylcytidine modification and their combination. In addition, they described the enhanced translation was partially contributed by suppressed elF2 $\alpha$ phosphorylation and increased ribosome pausing and density on the mRNA [(Svitkin, Cheng et al. 2017)].

mRNA obtained by IVT is not uniform in length and structure. They can contain contaminants such as short RNAs generated from abortive transcription and double-stranded RNAs generated from RNA-primed transcription from RNA templates, self-complementary $3^{\prime}$ extension, transcription runoffs and, RNAdependent RNA polymerase activity [(Milligan, Groebe et al. 1987); (Triana-Alonso, Dabrowski et al. 1995); (Arnaud-Barbe, Cheynet-Sauvion et al. 1998); (Nacheva and Berzal-Herranz 2003); (Mu, Greenwald et al. 
2018). These contaminants are potent inducers of immune responses and their removal requires mRNA purification after IVT [(Kariko, Muramatsu et al. 2008); (Kariko, Muramatsu et al. 2011)]. The purification is mostly done using chromatography to separate appropriately-sized mRNA from free nucleoside triphosphates, short RNA and DNA template [(Kim, McKenna et al. 2007); (McKenna, Kim et al. 2007)]. The elimination of double-stranded RNA requires high-performance liquid chromatography (HPLC) purification [(Kariko, Muramatsu et al. 2011); (Weissman, Pardi et al. 2013)]. These procedures are now used by most of mRNA-producing companies.

\section{3 mRNA-based therapeutic for osteogenesis}

mRNA as a potential therapeutic extends from vaccination to protein replacement therapy once modified mRNA was shown to facilitate in vivo exogenous mRNA-mediated protein expression with no or low immunogenicity [(Kariko, Muramatsu et al. 2008); (Kormann, Hasenpusch et al. 2011)]. Zangi et al. injected modified RNA encoding human VEGF-A into mouse heart with myocardial infarction [(Zangi, Lui et al. 2013)]. The VEGF-A expressed from modified mRNA significantly decreased the infarct size and enhanced the survival rate of recipients.

\subsubsection{BMPs replacement therapy}

For bone regeneration, recombinant BMPs have been used in therapy for over 40 years (Urist and Strates 2009). As dominant osteoinductive factors, BMPs have been delivered into the site that needs bone regeneration in the form of recombinant protein [(McKay, Peckham et al. 2007)] or via plasmid encoding BMP gene used as naked or vectorized form (Fang, Zhu et al. 1996);(Khorsand, Nicholson et al. 2017). The outcomes were promising, and the drawbacks were also apparent, as mentioned previously. Elangovan et al. employed modified mRNA encoding BMP-2 to enhance bone regeneration in vitro and in vivo (Elangovan, Khorsand et al. 2015). Using IFNa as a marker, combined modification of pseudouridine and 5-methylcytidine almost entirely circumvented unmodified mRNA induced immune response. They compared the osteoblastic differentiation induction between the modified BMP2 mRNA and its pDNA counterpart. Bone Marrow-derived Stem Cells (BMSCs) transfected with polyethylenimine (PEI)complexed modified mRNA (branched PEI, mol. wt. $25 \mathrm{kDa}$ ) yielded three times more BMP2 in the cell culture medium than cells transfected with pDNA. The osteogenic differentiation markers expression, such as alkaline phosphatase (ALP), osteocalcin (OCN), were also higher in the modified mRNA group. As a result, implanting a collagen scaffold containing modified mRNA polyplexes into rat calvarial defects showed 3.94-fold higher BV/TV (mineralized bone volume as a fraction of the total tissue volume of 
interest) in defect site compared to empty scaffold control. This study, for the first time, verified the safety and efficacy of using modified mRNA coding an osteogenic factor for bone regeneration. It also demonstrated the potential of modified mRNA-loaded scaffold as a novel bone graft substitute. Similarly, BMP-2 mRNA bearing methylcytidine and 2-thiouridine modification exhibited greater bone formation capacity [(Balmayor, Geiger et al. 2016); (Badieyan, Berezhanskyy et al. 2016); (Balmayor, Geiger et al. 2017). Balmayor et al. prepared modified mRNA coding human BMP-2 by replacing $25 \%$ cytidine and $25 \%$ uridine with methylcytidine and 2-thiouridine. Adipo-derived mesenchymal stem cells (AMSCs) showed osteogenic differentiation once transfected with this modified BMP-2 mRNA through lipofection or magnetofection (Badieyan, Berezhanskyy et al. 2016). Interestingly, AMSCs osteogenic differentiation was dose-dependent. For in vivo osteogenesis, liposomal formulation of modified BMP-2 mRNA mixed with a fibrin matrix was implanted into rat femur hole model. Two weeks post-operation, rats treated with modified BMP-2 mRNA obtained 2-fold more callus tissue than fibrin matrix alone.

Most of studies on bone regeneration have been based on the use of BMP2 since it is considered as one of the most osteogenic factors. A recent study highlighted that BMP-9 could be also used as an alternative. The efficiency of modified mRNA coding BMP-2 or BMP-9 to induce in vitro osteogenic induction and in vivo bone regeneration have been compared in a recent report(Khorsand, Elangovan et al. 2017). BMSCs transfected with PEI-complexed modified BMP-9 had a significant increase in ALP gene expression and calcium deposition compared to modified BMP-2 mRNA, but not in Runx2 and OCN genes expression. Implanting collagen matrices containing modified BMP-9 mRNA or BMP-2 into rat calvarial defect resulted in a similar ratio of bone volume to tissue volume. However, modified BMP-9 groups had 2-fold more density in connective tissue than BMP-2 groups, which is consistent with the in vitro observation.

Table 2: Summary of published studies using mRNA for in vivo bone regeneration.

\begin{tabular}{|c|c|c|c|c|c|}
\hline Gene & $\begin{array}{c}\text { Nucleotides } \\
\text { modification in IVT } \\
\text { mRNA }\end{array}$ & vector & Scaffold/cells & In vivo model & Ref. \\
\hline BMP-2 & $\Psi_{(1)}{ }^{*}$ and $\mathrm{m} \mathrm{C}_{(1)}$ & $\begin{array}{l}\text { Branched PEI } \\
(25 \mathrm{kDa})\end{array}$ & $\begin{array}{l}\text { Collagen sponge } \\
\text { containing } 25 \mu \mathrm{g} \\
\text { mRNA polyplexes }\end{array}$ & $\begin{array}{l}\text { Rat calvarial } \\
\text { defect-5 mm } \\
\text { diameter }\end{array}$ & $\begin{array}{l}\text { (Elangovan, } \\
\text { Khorsand et al. } \\
\text { 2015) }\end{array}$ \\
\hline BMP-2 & $\mathrm{s} 2 \mathrm{U}_{(0.25)}$ and $\mathrm{m} 5 \mathrm{C}_{(0.25)}$ & $\begin{array}{l}\text { cationic lipid } \\
\text { C12-EPE with } \\
\text { helper lipids } \\
\text { DOPE, } \\
\text { cholesterol, and } \\
\text { DMPE-PEG 2k }\end{array}$ & $\begin{array}{l}\text { Fibrin gel loaded } \\
\text { with } 2.5 \mu \mathrm{g} \text { mRNA } \\
\text { lipoplexes }\end{array}$ & $\begin{array}{l}\text { Rat femur } \\
\text { diaphysis } \\
\text { transcortical } \\
\text { bone defect- } \\
2 \mathrm{~mm} \text { diameter }\end{array}$ & $\begin{array}{l}\text { (Balmayor, Geiger } \\
\text { et al. 2016) }\end{array}$ \\
\hline
\end{tabular}




\begin{tabular}{|c|c|c|c|c|c|}
\hline BMP-2 & $\mathrm{s} 2 \mathrm{U}_{(0.25)}$ and $\mathrm{m} 5 \mathrm{C}_{(0.25)}$ & $\begin{array}{l}\text { cationic lipid } \\
\text { C12-EPE with } \\
\text { helper } \\
\text { DPPC and } \\
\text { cholesterol, and } \\
\text { DMG-PEG2K }\end{array}$ & $\begin{array}{l}\text { Collagen sponge } \\
\text { containing } 2.5 \mu \mathrm{g} \\
\text { mRNA lipoplexes }\end{array}$ & $\begin{array}{l}\text { Rat femur } \\
\text { diaphysis } \\
\text { transcortical } \\
\text { bone defect- } \\
2 \mathrm{~mm} \text { diameter }\end{array}$ & $\begin{array}{l}\text { (Badieyan, } \\
\text { Berezhanskyy et } \\
\text { al. 2016) }\end{array}$ \\
\hline $\begin{array}{l}\text { BMP- } \\
2 / 9\end{array}$ & $\Psi_{(1)}$ and $\mathrm{m} 5 \mathrm{C}_{(1)}$ & $\begin{array}{l}\text { Branched PEI } \\
\text { (mol. wt. } 25 \\
\text { kDa) }\end{array}$ & $\begin{array}{l}\text { Freeze dried } \\
\text { collagen scaffold } \\
\text { containing } 50 \mu \mathrm{g} \\
\text { mRNA polyplexes }\end{array}$ & $\begin{array}{l}\text { Rat calvarial } \\
\text { defect-5 mm } \\
\text { diameter }\end{array}$ & $\begin{array}{l}\text { (Khorsand, } \\
\text { Elangovan et al. } \\
\text { 2017) }\end{array}$ \\
\hline BMP-9 & $\Psi_{(1)}$ and $m 5 C_{(1)}$ & $\begin{array}{l}\text { Branched PEI } \\
\text { (mol. wt. } 25 \\
\text { kDa) }\end{array}$ & $\begin{array}{l}\text { Freeze dried } \\
\text { collagen } \\
\text { membrane } \\
\text { containing } 10 \mu \mathrm{g} \\
\text { mRNA polyplexes }\end{array}$ & $\begin{array}{l}\text { Rat calvarial } \\
\text { defect-5 mm } \\
\text { diameter }\end{array}$ & $\begin{array}{l}\text { (Khorsand, } \\
\text { Elangovan et al. } \\
\text { 2018) }\end{array}$ \\
\hline BMP-2 & $5 \mathrm{IU}_{(0.35)} 5 \mathrm{IC}_{(0.075)}$ & $\begin{array}{l}\text { cationic lipid } \\
\text { C12-(2-3-2) } \\
\text { with helper } \\
\text { lipids DPPC, } \\
\text { cholesterol, and } \\
\text { DMG-PEG 2k }\end{array}$ & $\begin{array}{l}\text { Vacuum dried } \\
\text { collagen sponge } \\
\text { containing } 2.5 \mu \mathrm{g} \\
\text { or } 5 \mu \mathrm{g} \text { mRNA } \\
\text { lipoplexes }\end{array}$ & $\begin{array}{l}\text { Rat femoral } \\
\text { segmental bone } \\
\text { defect-5mm } \\
\text { diameter }\end{array}$ & $\begin{array}{l}\text { (Zhang, De La } \\
\text { Vega et al. 2018) }\end{array}$ \\
\hline
\end{tabular}

*: the subscripted value represents the proposition of modified nucleotides in the IVT mRNA; $\Psi$ : pseudouridine; m5C: 5-methylcytosine; 5IU: 5-iodo-uridine; 5IC: 5-iodo-cytidine; s2U: 2-thiouridine;

C12-EPE: DOPC: 1,2-Dioleoyl-sn-Glycero-3-Phosphocholine; DPPC: 1,2-dipalmitoyl-sn-glycero-3phosphocholine; DMG-PEG2K: 1,2-dimyristoyl-rac-glycero-3-methoxypolyethylene glycol-2000; DMPEPEG2K: 1,2-distearoyl-sn-glycero-3-phosphoethanolamine-N-[amino(polyethylene glycol)-2000;

\subsubsection{Reprogramming proteins replacement}

Stem cells with osteogenic differentiation capacity have great applications in engineering bone substitutes with biocompatible scaffolds for bone regeneration (Amini, Laurencin et al. 2012). Mesenchymal stem cells are good candidates due to their bispecific differentiation toward osteogenic lineages. However, their limited proliferation in elderly patients and multi-passage induced senescence limit their clinical applications (Jones and Yang 2011). On the contrary, iPSCs (induced pluripotent stem cells) derived from somatic cells, typically fibroblast reprogramming, have the potential to circumvent this obstacle, with a lower rate of iPSCs senescence after expansion, both in vitro and in vivo. [(Takahashi and Yamanaka 2006); (Takahashi, Tanabe et al. 2007)]. iPSCs showed osteogenic differentiation under stimulation of osteogenic factors (Teng, Liu et al. 2014); (Csobonyeiova, Polak et al. 2017).

Warren et al., reprogrammed fibroblasts to iPSCs by transfecting them with a mix of pseudouridine and 5-methylcytidine containing IVT mRNAs encoding reprogramming transcription factors which are KLF4/ cMYC/ OCT4/ SOX2 (KMOS) or KLF4/ c-MYC/ OCT4/ SOX2/ LIN28 (KMOSL), respectively [(Warren, Manos et al. 2010)]. The KMOSL mRNAs mix induced ESC-like colonies almost ten days earlier than the KMOS 
mRNAs mix, consistent with the previous report that LIN28 facilitated reprogramming [(Yu, Jin et al. 2017); (Hanna, Saha et al. 2009)].

\subsection{Challenges and perspectives}

Advancing the use of mRNA for bone regeneration requires an increase of cost-benefit value over traditional approaches such as rhBMP2 and pDNA. Although incorporation of modified nucleotides and HPLC purification of IVT mRNA improves its translation along with decreased activation of TLRs and PKR, the high cost remains a challenge. Optimization of the sequence of $5^{\prime}$-and $3^{\prime}$-UTR and ORF, is one reasonable approach to increase IVT mRNA stability and translation efficiency within cells [(Zhang, De La Vega et al. 2018)]. Asrani and colleagues provided an experimental framework for a high throughput screening assay to simultaneously evaluate hundreds of UTRs for optimized protein expression [(Asrani, Farelli et al. 2018)]. Translation efficiency enhancement resulting from sequence-engineering can even exceed nucleotides modification (pseudouridine) both in vitro and in vivo (Thess, Grund et al. 2015). However, to date, no universal UTRs can be translated across different genes and cell types.

Applying mRNA for bone regeneration will benefit from continuous efforts in RNA design particularly on circularization. Wesselhoeft et al. recently demonstrated that mRNA circularization yielded superior expression in vivo over linear mRNA, paralleled with decreased induction of TLRs (Wesselhoeft, Kowalski et al. 2019). Circularization of mRNA decreased TLR activation to the same extent as the inclusion of modified nucleotides in linear mRNA, demonstrating a new modality for therapeutic protein expression. A further advancement in the usage of mRNA for bone regeneration consists in sequence/structure optimization in osteogenic cells. Indeed, optimization of mRNA sequence has been mostly performed in dendritic cells or macrophages (Holtkamp, Kreiter et al. 2006); (Uchida, Kataoka et al. 2015); (Orlandini von Niessen, Poleganov et al. 2018), cancer cell lines (Trepotec, Aneja et al. 2019); (Wesselhoeft, Kowalski et al. 2018), fibroblasts (Hausburg, Na et al. 2015); (Ferizi, Aneja et al. 2016), epithelial cells (Andries, Mc Cafferty et al. 2015). But rarely on clinically-relevant human mesenchymal stem cells (Hausburg, Na et al. 2015). Based on the cell-type dependent effects of mRNA modifications on expression and immunogenicity (Uchida, Kataoka et al. 2015), incorporation of modified nucleotides should be tuned for MSCs.

Inspired by viruses impair host cells immune response, B18R protein, from Western vaccinia virus that binds to and neutralizes type I interferons, is frequently used as culture supplement after IVT mRNA transfection. (Alcamí, Symons et al. 2000); (Warren, Manos et al. 2010); (Yoshioka, Gros et al. 2013). Unlike B18R, Influenza A virus non-structural protein 1 (NS1) is a multiple functional protein blocking several steps in immune responses. Recent study showed that co-transfection of NS1 mRNA with 
reporter mRNA, reduced immune response and increased reporter protein expression (Phua, Liu et al. 2017). NS1 from A/Texas/36/91 strain exhibited better performance than pseudouridine modification.

Transient expression is the inherent property of mRNA. The one-shot high expression is sufficient for vaccination, but sometimes not for protein-replacement therapies. For instance, to reconstruct bone nonunion continuous expression of osteogenic factors is needed. Entrapped mRNA complexes into a scaffold, sustained release of mRNA complexes resulting in cell multi-transfection and extended protein expression period. Hydrogels have been employed in vitro and in vivo as a therapeutic carrier to promote tissue formation. NHI3T3 cells encapsulated in fibrin hydrogel with $1 \mu \mathrm{g}$ pDNA coding firfly luciferase (fluc) expressed fluc for ten days with less fluc decrease in first 6 days (des Rieux, Shikanov et al. 2009).

Alternatively, Yoshioka et al. synthesized a self-replicating mRNA (RepRNA) for long-term multiple protein expression (Yoshioka, Gros et al. 2013). The proteins expressed from the RepRNA lasted for two weeks by a single-dose transfection. The polycistronic strategy suitable for bone regeneration as well, as several factors work synergistically in this process (Hankenson, Gagne et al. 2015).

\section{Conclusion}

In this review we described applications of mRNA and siRNA for bone regeneration. While the preclinical efficacy of RNA for bone regeneration has been demonstrated (Balmayor, Geiger et al. 2017); (Ghadakzadeh, Mekhail et al. 2016), the road to clinical evaluation requires evaluation in non-Human Primates. Bone is one of the dynamic tissues that has to support the body. Therefore, it involves many signaling pathways that have to be taken into account when building the therapeutic strategies. It I still highly challenging to restore large bone defect or nonunion fractures. The estimation is about one million of procedures that are occurring every year in Europe and the market estimated around $€ 5$ billion. Progresses of RNA for bone regeneration will surely involve a combination of mRNAs encoding osteoinductive proteins with siRNAs targeting critical regulators of bone formation to maximize fracture resorption. The success of bone regeneration is highly dependent on osteogenic cells, their microenvironment and the mechanical and structural properties of the extracellular matrix. The selection of the right 3D scaffold is crucial to restore and maintain the regeneration process. These last years, 3Dprinted templates have been proposed to fabricate patient-specific. Their preparation process is claimed to be easy, reproducible and can have specific micro-architecture with complex configuration (Zhang, Yang et al. 2019). However, the challenge is to get the right physical and biological properties and degradation, which must be in adequation with bone defect size and site. Hybrid 3D scaffold made with 
bioactive and inorganic materials appeared to have good-compromised features. Incorporation RNA therapeutics in such scaffold will allow to create a patient specific bone graft on demand.

\section{Acknowledgment}

This work is supported by CNRS and University of Orléans. WANG Pinpin thanks the financial support from China Scholarship Council.

\section{Reference}

Abe, E., M. Yamamoto, Y. Taguchi, B. Lecka-Czernik, C. A. O'Brien, A. N. Economides, N. Stahl, R. L. Jilka and S. C. Manolagas (2000). "Essential requirement of BMPs-2/4 for both osteoblast and osteoclast formation in murine bone marrow cultures from adult mice: antagonism by noggin." $\mathrm{J}$ Bone Miner Res 15(4): 663-673.

Adams, D., O. B. Suhr, P. J. Dyck, W. J. Litchy, R. G. Leahy, J. Chen, J. Gollob and T. Coelho (2017). "Trial design and rationale for APOLLO, a Phase 3, placebo-controlled study of patisiran in patients with hereditary ATTR amyloidosis with polyneuropathy." BMC Neurol 17(1): 181.

Agrawal, N., P. V. N. Dasaradhi, A. Mohmmed, P. Malhotra, R. K. Bhatnagar and S. K. Mukherjee (2003). "RNA Interference: Biology, Mechanism, and Applications." Microbiology and Molecular Biology Reviews 67(4): 657-685.

Alcamí, A., J. A. Symons and G. L. Smith (2000). "The Vaccinia Virus Soluble Alpha/Beta Interferon (IFN) Receptor Binds to the Cell Surface and Protects Cells from the Antiviral Effects of IFN." Journal of Virology 74(23): 11230-11239.

Alexopoulou, L., A. C. Holt, R. Medzhitov and R. A. Flavell (2001). "Recognition of double-stranded RNA and activation of NF-kappaB by Toll-like receptor 3." Nature 413(6857): 732-738.

Amini, A. R., C. T. Laurencin and S. P. Nukavarapu (2012). "Bone tissue engineering: recent advances and challenges." Crit Rev Biomed Eng 40(5): 363-408.

Anderson, B. R., H. Muramatsu, S. R. Nallagatla, P. C. Bevilacqua, L. H. Sansing, D. Weissman and K. Kariko (2010). "Incorporation of pseudouridine into mRNA enhances translation by diminishing PKR activation." Nucleic Acids Res 38(17): 5884-5892.

Andries, O., S. Mc Cafferty, S. C. De Smedt, R. Weiss, N. N. Sanders and T. Kitada (2015). "N(1)methylpseudouridine-incorporated mRNA outperforms pseudouridine-incorporated mRNA by providing enhanced protein expression and reduced immunogenicity in mammalian cell lines and mice." J Control Release 217: 337-344.

Arnaud-Barbe, N., V. Cheynet-Sauvion, G. Oriol, B. Mandrand and F. Mallet (1998). "Transcription of RNA templates by T7 RNA polymerase." Nucleic Acids Res 26(15): 3550-3554.

Asrani, K. H., J. D. Farelli, M. R. Stahley, R. L. Miller, C. J. Cheng, R. R. Subramanian and J. M. Brown (2018). "Optimization of mRNA untranslated regions for improved expression of therapeutic mRNA." RNA Biol: 1-7.

Badieyan, Z. S., T. Berezhanskyy, M. Utzinger, M. K. Aneja, D. Emrich, R. Erben, C. Schuler, P. Altpeter, M. Ferizi, G. Hasenpusch, C. Rudolph and C. Plank (2016). "Transcript-activated collagen matrix as sustained mRNA delivery system for bone regeneration." J Control Release 239: 137-148.

Balmayor, E. R., J. P. Geiger, M. K. Aneja, T. Berezhanskyy, M. Utzinger, O. Mykhaylyk, C. Rudolph and C. Plank (2016). "Chemically modified RNA induces osteogenesis of stem cells and human tissue explants as well as accelerates bone healing in rats." Biomaterials 87: 131-146. 
Balmayor, E. R., J. P. Geiger, C. Koch, M. K. Aneja, M. van Griensven, C. Rudolph and C. Plank (2017). "Modified mRNA for BMP-2 in Combination with Biomaterials Serves as a Transcript-Activated Matrix for Effectively Inducing Osteogenic Pathways in Stem Cells." Stem Cells Dev 26(1): 25-34.

Banerjee, A. K. (1980). "5'-terminal cap structure in eucaryotic messenger ribonucleic acids." Microbiol Rev 44(2): 175-205.

Bashirullah, A., R. L. Cooperstock and H. D. Lipshitz (2001). "Spatial and temporal control of RNA stability." Proc Natl Acad Sci U S A 98(13): 7025-7028.

Boyce, B. F., T. Yoneda, C. Lowe, P. Soriano and G. R. Mundy (1992). "Requirement of pp60c-src expression for osteoclasts to form ruffled borders and resorb bone in mice." J Clin Invest 90(4): 1622-

1627.

Cai, A., M. Jankowska-Anyszka, A. Centers, L. Chlebicka, J. Stepinski, R. Stolarski, E. Darzynkiewicz and R. E. Rhoads (1999). "Quantitative assessment of mRNA cap analogues as inhibitors of in vitro translation." Biochemistry 38(26): 8538-8547.

Chaudhary, A., S. Srivastava and S. Garg (2011). "Development of a software tool and criteria evaluation for efficient design of small interfering RNA." Biochem Biophys Res Commun 404(1): 313-320.

Chen, C., H. Uludag, Z. Wang and H. Jiang (2012). "Noggin suppression decreases BMP-2-induced osteogenesis of human bone marrow-derived mesenchymal stem cells in vitro." J Cell Biochem 113(12): 3672-3680.

Chen, C. Y., R. Gherzi, S. E. Ong, E. L. Chan, R. Raijmakers, G. J. Pruijn, G. Stoecklin, C. Moroni, M. Mann and M. Karin (2001). "AU binding proteins recruit the exosome to degrade ARE-containing mRNAs." Cell 107(4): 451-464.

Chen, G., C. Deng and Y. P. Li (2012). "TGF-beta and BMP signaling in osteoblast differentiation and bone formation." Int J Biol Sci 8(2): 272-288.

Choi, B., Z. K. Cui, S. Kim, J. Fan, B. M. Wu and M. Lee (2015). "Glutamine-chitosan modified calcium phosphate nanoparticles for efficient siRNA delivery and osteogenic differentiation." $\mathrm{J}$ Mater Chem B 3(31): 6448-6455.

Coller, J. and R. Parker (2004). "Eukaryotic mRNA decapping." Annu Rev Biochem 73: 861-890.

Contreras, R., H. Cheroutre, W. Degrave and W. Fiers (1982). "Simple, efficient in vitro synthesis of capped RNA useful for direct expression of cloned eukaryotic genes." Nucleic Acids Res 10(20): 63536362.

Cosman, F., D. B. Crittenden, J. D. Adachi, N. Binkley, E. Czerwinski, S. Ferrari, L. C. Hofbauer, E. Lau, E. M. Lewiecki, A. Miyauchi, C. A. Zerbini, C. E. Milmont, L. Chen, J. Maddox, P. D. Meisner, C. Libanati and A. Grauer (2016). "Romosozumab Treatment in Postmenopausal Women with Osteoporosis." N Engl J Med 375(16): 1532-1543.

Couttet, P., M. Fromont-Racine, D. Steel, R. Pictet and T. Grange (1997). "Messenger RNA deadenylylation precedes decapping in mammalian cells." Proc Natl Acad Sci U S A 94(11): 5628-5633. Csobonyeiova, M., S. Polak, R. Zamborsky and L. Danisovic (2017). "iPS cell technologies and their prospect for bone regeneration and disease modeling: A mini review." J Adv Res 8(4): 321-327.

Cui, Z. K., J. Fan, S. Kim, O. Bezouglaia, A. Fartash, B. M. Wu, T. Aghaloo and M. Lee (2015). "Delivery of siRNA via cationic Sterosomes to enhance osteogenic differentiation of mesenchymal stem cells." $\underline{J}$ Control Release 217: 42-52.

Dan, M., D. Zheng, L. L. Field and V. Bonnevie-Nielsen (2012). "Induction and activation of antiviral enzyme 2',5'-oligoadenylate synthetase by in vitro transcribed insulin mRNA and other cellular RNAs." Mol Biol Rep 39(7): 7813-7822.

de Fougerolles, A., H. P. Vornlocher, J. Maraganore and J. Lieberman (2007). "Interfering with disease: a progress report on siRNA-based therapeutics." Nat Rev Drug Discov 6(6): 443-453.

des Rieux, A., A. Shikanov and L. D. Shea (2009). "Fibrin hydrogels for non-viral vector delivery in vitro." J Control Release 136(2): 148-154. 
Devlin, R. D., Z. Du, R. C. Pereira, R. B. Kimble, A. N. Economides, V. Jorgetti and E. Canalis (2003). "Skeletal overexpression of noggin results in osteopenia and reduced bone formation." Endocrinology 144(5): 1972-1978.

Dimitriou, R., E. Tsiridis and P. V. Giannoudis (2005). "Current concepts of molecular aspects of bone healing." Injury 36(12): 1392-1404.

Dorn, G., S. Patel, G. Wotherspoon, M. Hemmings-Mieszczak, J. Barclay, F. J. Natt, P. Martin, S. Bevan, A. Fox, P. Ganju, W. Wishart and J. Hall (2004). "siRNA relieves chronic neuropathic pain." Nucleic Acids Res 32(5): e49.

Edmonds, M., M. H. Vaughan, Jr. and H. Nakazato (1971). "Polyadenylic acid sequences in the heterogeneous nuclear RNA and rapidly-labeled polyribosomal RNA of HeLa cells: possible evidence for a precursor relationship." Proc Natl Acad Sci U S A 68(6): 1336-1340.

Egermann, M., E. Schneider, C. H. Evans and A. W. Baltzer (2005). "The potential of gene therapy for fracture healing in osteoporosis." Osteoporosis International 16(S02): S120-S128.

Elangovan, S., B. Khorsand, A. V. Do, L. Hong, A. Dewerth, M. Kormann, R. D. Ross, D. R. Sumner, C. Allamargot and A. K. Salem (2015). "Chemically modified RNA activated matrices enhance bone regeneration." J Control Release 218: 22-28.

Elbashir, S. M., J. Harborth, W. Lendeckel, A. Yalcin, K. Weber and T. Tuschl (2001). "Duplexes of 21nucleotide RNAs mediate RNA interference in cultured mammalian cells." Nature 411(6836): 494-498. Elbashir, S. M., W. Lendeckel and T. Tuschl (2001). "RNA interference is mediated by 21- and 22nucleotide RNAs." Genes Dev 15(2): 188-200.

Evans, C. H. and J. Huard (2015). "Gene therapy approaches to regenerating the musculoskeletal system." Nat Rev Rheumatol 11(4): 234-242.

Fang, J., Y. Y. Zhu, E. Smiley, J. Bonadio, J. P. Rouleau, S. A. Goldstein, L. K. McCauley, B. L. Davidson and B. J. Roessler (1996). "Stimulation of new bone formation by direct transfer of osteogenic plasmid genes." Proc Natl Acad Sci U S A 93(12): 5753-5758.

Ferizi, M., M. K. Aneja, E. R. Balmayor, Z. S. Badieyan, O. Mykhaylyk, C. Rudolph and C. Plank (2016). "Human cellular CYBA UTR sequences increase mRNA translation without affecting the half-life of recombinant RNA transcripts." Sci Rep 6: 39149.

Filleur, S., A. Courtin, S. Ait-Si-Ali, J. Guglielmi, C. Merle, A. Harel-Bellan, P. Clezardin and F. Cabon (2003). "SiRNA-mediated inhibition of vascular endothelial growth factor severely limits tumor resistance to antiangiogenic thrombospondin-1 and slows tumor vascularization and growth." Cancer Res 63(14): 3919-3922.

Fire, A. (1999). "RNA-triggered gene silencing." Trends Genet 15(9): 358-363.

Fischer, L., G. Boland and R. S. Tuan (2002). "Wnt-3A enhances bone morphogenetic protein-2-mediated chondrogenesis of murine C3H10T1/2 mesenchymal cells." J Biol Chem 277(34): 30870-30878.

Fisher, S. and M. E. Halpern (1999). "Patterning the zebrafish axial skeleton requires early chordin function." Nat Genet 23(4): 442-446.

Frattini, A., P. J. Orchard, C. Sobacchi, S. Giliani, M. Abinun, J. P. Mattsson, D. J. Keeling, A. K. Andersson, P. Wallbrandt, L. Zecca, L. D. Notarangelo, P. Vezzoni and A. Villa (2000). "Defects in TCIRG1 subunit of the vacuolar proton pump are responsible for a subset of human autosomal recessive osteopetrosis." Nat Genet 25(3): 343-346.

Freund, I., T. Eigenbrod, M. Helm and A. H. Dalpke (2019). "RNA Modifications Modulate Activation of Innate Toll-Like Receptors." Genes (Basel) 10(2).

Gallie, D. R. (1998). "A tale of two termini: a functional interaction between the termini of an mRNA is a prerequisite for efficient translation initiation." Gene 216(1): 1-11.

Gazzerro, E., A. Smerdel-Ramoya, S. Zanotti, L. Stadmeyer, D. Durant, A. N. Economides and E. Canalis (2007). "Conditional deletion of gremlin causes a transient increase in bone formation and bone mass." J Biol Chem 282(43): 31549-31557. 
Genant, H. K., C. Cooper, G. Poor, I. Reid, G. Ehrlich, J. Kanis, B. E. Nordin, E. Barrett-Connor, D. Black, J. P. Bonjour, B. Dawson-Hughes, P. D. Delmas, J. Dequeker, S. Ragi Eis, C. Gennari, O. Johnell, C. C. Johnston, Jr., E. M. Lau, U. A. Liberman, R. Lindsay, T. J. Martin, B. Masri, C. A. Mautalen, P. J. Meunier, N. Khaltaev and et al. (1999). "Interim report and recommendations of the World Health Organization Task-Force for Osteoporosis." Osteoporos Int 10(4): 259-264.

Ghadakzadeh, S., M. Mekhail, A. Aoude, R. Hamdy and M. Tabrizian (2016). "Small Players Ruling the Hard Game: siRNA in Bone Regeneration." J Bone Miner Res 31(3): 475-487.

Giannoudis, P. V., O. Faour, T. Goff, N. Kanakaris and R. Dimitriou (2011). "Masquelet technique for the treatment of bone defects: tips-tricks and future directions." Injury 42(6): 591-598.

Goldberg, V. M. and S. Stevenson (1987). "Natural history of autografts and allografts." Clin Orthop Relat Res (225): 7-16.

Grier, A. E., S. Burleigh, J. Sahni, C. A. Clough, V. Cardot, D. C. Choe, M. C. Krutein, D. J. Rawlings, M. C. Jensen, A. M. Scharenberg and K. Jacoby (2016). "pEVL: A Linear Plasmid for Generating mRNA IVT Templates With Extended Encoded Poly(A) Sequences." Mol Ther Nucleic Acids 5: e306.

Grudzien-Nogalska, E., J. Jemielity, J. Kowalska, E. Darzynkiewicz and R. E. Rhoads (2007).

"Phosphorothioate cap analogs stabilize mRNA and increase translational efficiency in mammalian cells." RNA 13(10): 1745-1755.

Hankenson, K. D., K. Gagne and M. Shaughnessy (2015). "Extracellular signaling molecules to promote fracture healing and bone regeneration." Adv Drug Deliv Rev 94: 3-12.

Hanna, J., K. Saha, B. Pando, J. van Zon, C. J. Lengner, M. P. Creyghton, A. van Oudenaarden and R. Jaenisch (2009). "Direct cell reprogramming is a stochastic process amenable to acceleration." Nature 462(7273): 595-601.

Hannon, G. J. (2002). "RNA interference." Nature 418(6894): 244-251.

Hausburg, F., S. Na, N. Voronina, A. Skorska, P. Muller, G. Steinhoff and R. David (2015). "Defining optimized properties of modified mRNA to enhance virus- and DNA- independent protein expression in adult stem cells and fibroblasts." Cell Physiol Biochem 35(4): 1360-1371.

Heil, F., H. Hemmi, H. Hochrein, F. Ampenberger, C. Kirschning, S. Akira, G. Lipford, H. Wagner and S. Bauer (2004). "Species-specific recognition of single-stranded RNA via toll-like receptor 7 and 8." Science 303(5663): 1526-1529.

Hofbauer, L. C. and A. E. Heufelder (2001). "Role of receptor activator of nuclear factor-kappaB ligand and osteoprotegerin in bone cell biology." J Mol Med (Berl) 79(5-6): 243-253.

Hollick, R. J. and D. M. Reid (2011). "Role of bisphosphonates in the management of postmenopausal osteoporosis: an update on recent safety anxieties." Menopause Int 17(2): 66-72.

Holtkamp, S., S. Kreiter, A. Selmi, P. Simon, M. Koslowski, C. Huber, O. Tureci and U. Sahin (2006).

"Modification of antigen-encoding RNA increases stability, translational efficacy, and T-cell stimulatory capacity of dendritic cells." Blood 108(13): 4009-4017.

Horikami, S. M., F. De Ferra and S. A. Moyer (1984). "Characterization of the infections of permissive and nonpermissive cells by host range mutants of vesicular stomatitis virus defective in RNA methylation."

Virology 138(1): 1-15.

Hsu, D. R., A. N. Economides, X. Wang, P. M. Eimon and R. M. Harland (1998). "The Xenopus dorsalizing factor Gremlin identifies a novel family of secreted proteins that antagonize BMP activities." Mol Cell 1(5): 673-683.

Hu, K., H. Sun, B. Gui and C. Sui (2017). "Gremlin-1 suppression increases BMP-2-induced osteogenesis of human mesenchymal stem cells." Mol Med Rep 15(4): 2186-2194.

Huang, J., C. Lin, J. Fang, X. Li, J. Wang, S. Deng, S. Zhang, W. Su, X. Feng, B. Chen, D. Cheng and X. Shuai (2018). "pH-Sensitive Nanocarrier-Mediated Codelivery of Simvastatin and Noggin siRNA for Synergistic Enhancement of Osteogenesis." ACS Appl Mater Interfaces 10(34): 28471-28482. 
Huang, R. L., Y. Yuan, J. Tu, G. M. Zou and Q. Li (2014). "Opposing TNF-alpha/IL-1beta- and BMP-2activated MAPK signaling pathways converge on Runx2 to regulate BMP-2-induced osteoblastic differentiation." Cell Death Dis 5: e1187.

Im, G. I. (2013). "Nonviral gene transfer strategies to promote bone regeneration." J Biomed Mater Res A 101(10): 3009-3018.

Inada, T., A. Tamura, M. Terauchi, S. Yamaguchi and N. Yui (2018). "A silencing-mediated enhancement of osteogenic differentiation by supramolecular ternary siRNA polyplexes comprising biocleavable cationic polyrotaxanes and anionic fusogenic peptides." Biomater Sci 6(2): 440-450.

Jackson, R. J. (1993). "Cytoplasmic regulation of mRNA function: the importance of the 3' untranslated region." Cell 74(1): 9-14.

Jansen, R. P. (2001). "mRNA localization: message on the move." Nat Rev Mol Cell Biol 2(4): 247-256.

Jemielity, J., T. Fowler, J. Zuberek, J. Stepinski, M. Lewdorowicz, A. Niedzwiecka, R. Stolarski, E.

Darzynkiewicz and R. E. Rhoads (2003). "Novel "anti-reverse" cap analogs with superior translational properties." RNA 9(9): 1108-1122.

Jirikowski, G. F., P. P. Sanna, D. Maciejewski-Lenoir and F. E. Bloom (1992). "Reversal of diabetes insipidus in Brattleboro rats: intrahypothalamic injection of vasopressin mRNA." Science 255(5047): 996998.

Jones, E. and X. Yang (2011). "Mesenchymal stem cells and bone regeneration: current status." Injury 42(6): 562-568.

Kariko, K., M. Buckstein, H. Ni and D. Weissman (2005). "Suppression of RNA recognition by Toll-like receptors: the impact of nucleoside modification and the evolutionary origin of RNA." Immunity 23(2): 165-175.

Kariko, K., H. Muramatsu, J. Ludwig and D. Weissman (2011). "Generating the optimal mRNA for therapy: HPLC purification eliminates immune activation and improves translation of nucleosidemodified, protein-encoding mRNA." Nucleic Acids Res 39(21): e142.

Kariko, K., H. Muramatsu, F. A. Welsh, J. Ludwig, H. Kato, S. Akira and D. Weissman (2008).

"Incorporation of pseudouridine into mRNA yields superior nonimmunogenic vector with increased translational capacity and biological stability." Mol Ther 16(11): 1833-1840.

Kariko, K., H. Ni, J. Capodici, M. Lamphier and D. Weissman (2004). "mRNA is an endogenous ligand for Toll-like receptor 3." J Biol Chem 279(13): 12542-12550.

Khorsand, B., S. Elangovan, L. Hong, A. Dewerth, M. S. Kormann and A. K. Salem (2017). "A Comparative Study of the Bone Regenerative Effect of Chemically Modified RNA Encoding BMP-2 or BMP-9." AAPS J 19(2): 438-446.

Khorsand, B., N. Nicholson, A. V. Do, J. E. Femino, J. A. Martin, E. Petersen, B. Guetschow, D. C. Fredericks and A. K. Salem (2017). "Regeneration of bone using nanoplex delivery of FGF-2 and BMP-2 genes in diaphyseal long bone radial defects in a diabetic rabbit model." J Control Release 248: 53-59. Kim, I., S. A. McKenna, E. Viani Puglisi and J. D. Puglisi (2007). "Rapid purification of RNAs using fast performance liquid chromatography (FPLC)." RNA 13(2): 289-294.

Koide, M., S. Kinugawa, N. Takahashi and N. Udagawa (2010). "Osteoclastic bone resorption induced by innate immune responses." Periodontol 2000 54(1): 235-246.

Konarska, M. M., R. A. Padgett and P. A. Sharp (1984). "Recognition of cap structure in splicing in vitro of mRNA precursors." Cell 38(3): 731-736.

Kormann, M. S. D., G. Hasenpusch, M. K. Aneja, G. Nica, A. W. Flemmer, S. Herber-Jonat, M. Huppmann, L. E. Mays, M. Illenyi, A. Schams, M. Griese, I. Bittmann, R. Handgretinger, D. Hartl, J. Rosenecker and C. Rudolph (2011). "Expression of therapeutic proteins after delivery of chemically modified mRNA in mice." Nature Biotechnology 29: 154.

Kozak, M. (1987). "An analysis of 5'-noncoding sequences from 699 vertebrate messenger RNAs." Nucleic Acids Res 15(20): 8125-8148. 
Kozak, M. (2005). "Regulation of translation via mRNA structure in prokaryotes and eukaryotes." Gene 361: 13-37.

Krishnan, V., H. U. Bryant and O. A. Macdougald (2006). "Regulation of bone mass by Wnt signaling." J Clin Invest 116(5): 1202-1209.

Kwong, F. N., S. M. Richardson and C. H. Evans (2008). "Chordin knockdown enhances the osteogenic differentiation of human mesenchymal stem cells." Arthritis Res Ther 10(3): R65.

Lam, J. K. W., M. Y. T. Chow, Y. Zhang and S. W. S. Leung (2015). "siRNA Versus miRNA as Therapeutics for Gene Silencing." Molecular Therapy - Nucleic Acids 4: e252.

Langberg, S. R. and B. Moss (1981). "Post-transcriptional modifications of mRNA. Purification and characterization of cap I and cap II RNA (nucleoside-2'-)-methyltransferases from HeLa cells." $\underline{\text { J Biol }}$ Chem 256(19): 10054-10060.

Li, B., X. Luo and Y. Dong (2016). "Effects of Chemically Modified Messenger RNA on Protein Expression." Bioconjug Chem 27(3): 849-853.

Liu, X. (2016). "Bone site-specific delivery of siRNA." J Biomed Res 30(4): 264-271.

Lo, H. J., H. K. Huang and T. F. Donahue (1998). "RNA polymerase I-promoted HIS4 expression yields

uncapped, polyadenylated mRNA that is unstable and inefficiently translated in Saccharomyces cerevisiae." Mol Cell Biol 18(2): 665-675.

Longo, K. A., J. A. Kennell, M. J. Ochocinska, S. E. Ross, W. S. Wright and O. A. MacDougald (2002). "Wnt signaling protects 3T3-L1 preadipocytes from apoptosis through induction of insulin-like growth factors." J Biol Chem 277(41): 38239-38244.

Lowe, C., T. Yoneda, B. F. Boyce, H. Chen, G. R. Mundy and P. Soriano (1993). "Osteopetrosis in Srcdeficient mice is due to an autonomous defect of osteoclasts." Proc Natl Acad Sci U S A 90(10): 44854489.

Ma, Z., C. Yang, W. Song, Q. Wang, J. Kjems and S. Gao (2014). "Chitosan hydrogel as siRNA vector for prolonged gene silencing." J Nanobiotechnology 12: 23.

Malone, R. W., P. L. Felgner and I. M. Verma (1989). "Cationic liposome-mediated RNA transfection." Proc Natl Acad Sci U S A 86(16): 6077-6081.

Manaka, T., A. Suzuki, K. Takayama, Y. Imai, H. Nakamura and K. Takaoka (2011). "Local delivery of siRNA using a biodegradable polymer application to enhance BMP-induced bone formation." Biomaterials 32(36): 9642-9648.

Mao, B., W. Wu, G. Davidson, J. Marhold, M. Li, B. M. Mechler, H. Delius, D. Hoppe, P. Stannek, C. Walter, A. Glinka and C. Niehrs (2002). "Kremen proteins are Dickkopf receptors that regulate Wnt/betacatenin signalling." Nature 417(6889): 664-667.

Matsuo, H., H. Li, A. M. McGuire, C. M. Fletcher, A. C. Gingras, N. Sonenberg and G. Wagner (1997). "Structure of translation factor elF4E bound to m7GDP and interaction with 4E-binding protein." Nat Struct Biol 4(9): 717-724.

Maxhimer, J. B., J. P. Bradley and J. C. Lee (2015). "Signaling pathways in osteogenesis and osteoclastogenesis: Lessons from cranial sutures and applications to regenerative medicine." Genes Dis 2(1): 57-68.

McClung, M. R., A. Grauer, S. Boonen, M. A. Bolognese, J. P. Brown, A. Diez-Perez, B. L. Langdahl, J. Y. Reginster, J. R. Zanchetta, S. M. Wasserman, L. Katz, J. Maddox, Y. C. Yang, C. Libanati and H. G. Bone (2014). "Romosozumab in postmenopausal women with low bone mineral density." $\underline{\mathrm{N} \text { Engl J Med }}$ 370(5): 412-420.

McCormick, C. and D. A. Khaperskyy (2017). "Translation inhibition and stress granules in the antiviral immune response." Nat Rev Immunol 17(10): 647-660.

McKay, W. F., S. M. Peckham and J. M. Badura (2007). "A comprehensive clinical review of recombinant human bone morphogenetic protein-2 (INFUSE Bone Graft)." Int Orthop 31(6): 729-734. 
McKenna, S. A., I. Kim, E. V. Puglisi, D. A. Lindhout, C. E. Aitken, R. A. Marshall and J. D. Puglisi (2007). "Purification and characterization of transcribed RNAs using gel filtration chromatography." Nat Protoc 2(12): 3270-3277.

Mendecki, J., S. Y. Lee and G. Brawerman (1972). "Characteristics of the polyadenylic acid segment associated with messenger ribonucleic acid in mouse sarcoma 180 ascites cells." Biochemistry 11(5): 792-798.

Merino, R., J. Rodriguez-Leon, D. Macias, Y. Ganan, A. N. Economides and J. M. Hurle (1999). "The BMP antagonist Gremlin regulates outgrowth, chondrogenesis and programmed cell death in the developing limb." Development 126(23): 5515-5522.

Mignone, F., C. Gissi, S. Liuni and G. Pesole (2002). "Untranslated regions of mRNAs." Genome Biol 3(3): REVIEWSO004.

Miller, V. M., H. Xia, G. L. Marrs, C. M. Gouvion, G. Lee, B. L. Davidson and H. L. Paulson (2003). "Allelespecific silencing of dominant disease genes." Proc Natl Acad Sci U S A 100(12): 7195-7200.

Milligan, J. F., D. R. Groebe, G. W. Witherell and O. C. Uhlenbeck (1987). "Oligoribonucleotide synthesis using T7 RNA polymerase and synthetic DNA templates." Nucleic Acids Res 15(21): 8783-8798.

Mockey, M., C. Goncalves, F. P. Dupuy, F. M. Lemoine, C. Pichon and P. Midoux (2006). "mRNA transfection of dendritic cells: synergistic effect of ARCA mRNA capping with Poly(A) chains in cis and in trans for a high protein expression level." Biochem Biophys Res Commun 340(4): 1062-1068.

$\mathrm{Mu}, \mathrm{X}$., E. Greenwald, S. Ahmad and S. Hur (2018). "An origin of the immunogenicity of in vitro transcribed RNA." Nucleic Acids Res 46(10): 5239-5249.

Mukherjee, D., M. Gao, J. P. O'Connor, R. Raijmakers, G. Pruijn, C. S. Lutz and J. Wilusz (2002). "The mammalian exosome mediates the efficient degradation of mRNAs that contain AU-rich elements." EMBO J 21(1-2): 165-174.

Nacheva, G. A. and A. Berzal-Herranz (2003). "Preventing nondesired RNA-primed RNA extension catalyzed by T7 RNA polymerase." Eur J Biochem 270(7): 1458-1465.

Naito, Y. and K. Ui-Tei (2013). "Designing functional siRNA with reduced off-target effects." Methods Mol Biol 942: 57-68.

Nakashima, T., Y. Kobayashi, S. Yamasaki, A. Kawakami, K. Eguchi, H. Sasaki and H. Sakai (2000). "Protein expression and functional difference of membrane-bound and soluble receptor activator of NF-kappaB ligand: modulation of the expression by osteotropic factors and cytokines." Biochem Biophys Res Commun 275(3): 768-775.

Negishi-Koga, T., M. Shinohara, N. Komatsu, H. Bito, T. Kodama, R. H. Friedel and H. Takayanagi (2011). "Suppression of bone formation by osteoclastic expression of semaphorin 4D." Nat Med 17(11): 14731480.

Nguyen, M. K., O. Jeon, P. N. Dang, C. T. Huynh, D. Varghai, H. Riazi, A. McMillan, S. Herberg and E. Alsberg (2018). "RNA interfering molecule delivery from in situ forming biodegradable hydrogels for enhancement of bone formation in rat calvarial bone defects." Acta Biomaterialia 75: 105-114.

NIH Consensus Development Panel on Osteoporosis Prevention, D. and Therapy (2001). "Osteoporosis prevention, diagnosis, and therapy." JAMA 285(6): 785-795.

Orlandini von Niessen, A. G., M. A. Poleganov, C. Rechner, A. Plaschke, L. M. Kranz, S. Fesser, M. Diken, M. Lower, B. Vallazza, T. Beissert, V. Bukur, A. N. Kuhn, O. Tureci and U. Sahin (2018). "Improving mRNABased Therapeutic Gene Delivery by Expression-Augmenting 3' UTRs Identified by Cellular Library Screening." Mol Ther.

Ozcan, G., B. Ozpolat, R. L. Coleman, A. K. Sood and G. Lopez-Berestein (2015). "Preclinical and clinical development of siRNA-based therapeutics." Adv Drug Deliv Rev 87: 108-119.

Padhi, D., G. Jang, B. Stouch, L. Fang and E. Posvar (2011). "Single-dose, placebo-controlled, randomized study of AMG 785, a sclerostin monoclonal antibody." J Bone Miner Res 26(1): 19-26.

Pascolo, S. (2008). "Vaccination with messenger RNA (mRNA)." Handb Exp Pharmacol(183): 221-235. 
Pearce, J. J., G. Penny and J. Rossant (1999). "A mouse cerberus/Dan-related gene family." Dev Biol 209(1): 98-110.

Peng, J., E. L. Murray and D. R. Schoenberg (2008). "In vivo and in vitro analysis of poly(A) length effects on mRNA translation." Methods Mol Biol 419: 215-230.

Perrin, D. D. (1965). "Binding of tetracyclines to bone." Nature 208(5012): 787-788.

Phimphilai, M., Z. Zhao, H. Boules, H. Roca and R. T. Franceschi (2006). "BMP signaling is required for RUNX2-dependent induction of the osteoblast phenotype." J Bone Miner Res 21(4): 637-646.

Phua, K. K. L., Y. Liu and S. H. Sim (2017). "Non-linear enhancement of mRNA delivery efficiencies by influenza A derived NS1 protein engendering host gene inhibition property." Biomaterials 133: 29-36.

Piccolo, S., Y. Sasai, B. Lu and E. M. De Robertis (1996). "Dorsoventral patterning in Xenopus: inhibition of ventral signals by direct binding of chordin to BMP-4." Cell 86(4): 589-598.

Rawadi, G., B. Vayssiere, F. Dunn, R. Baron and S. Roman-Roman (2003). "BMP-2 controls alkaline phosphatase expression and osteoblast mineralization by a Wnt autocrine loop." J Bone Miner Res 18(10): 1842-1853.

Rios, C. N., R. J. Skoracki and A. B. Mathur (2012). "GNAS1 and PHD2 short-interfering RNA support bone regeneration in vitro and in an in vivo sheep model." Clin Orthop Relat Res 470(9): 2541-2553.

Robert Rozbruch, S., A. M. Weitzman, J. Tracey Watson, P. Freudigman, H. V. Katz and S. Ilizarov (2006). "Simultaneous treatment of tibial bone and soft-tissue defects with the llizarov method." J Orthop Trauma 20(3): 197-205.

Rodan, G. A. and T. J. Martin (2000). "Therapeutic approaches to bone diseases." Science 289(5484): 1508-1514.

Roush, K. (2011). "Prevention and treatment of osteoporosis in postmenopausal women: a review." Am J Nurs 111(8): 26-35; quiz 36-27.

Sachs, A. B., R. W. Davis and R. D. Kornberg (1987). "A single domain of yeast poly(A)-binding protein is necessary and sufficient for RNA binding and cell viability." Mol Cell Biol 7(9): 3268-3276.

Sahin, U., K. Kariko and O. Tureci (2014). "mRNA-based therapeutics--developing a new class of drugs." Nat Rev Drug Discov 13(10): 759-780.

Schilcher, J., K. Michaelsson and P. Aspenberg (2011). "Bisphosphonate use and atypical fractures of the femoral shaft." N Engl J Med 364(18): 1728-1737.

Schlake, T., A. Thess, M. Thran and I. Jordan (2018). "mRNA as novel technology for passive immunotherapy." Cell Mol Life Sci.

Scott, I. C., B. M. Steiglitz, T. G. Clark, W. N. Pappano and D. S. Greenspan (2000). "Spatiotemporal expression patterns of mammalian chordin during postgastrulation embryogenesis and in postnatal brain." Dev Dyn 217(4): 449-456.

Sezlev Bilecen, D., H. Uludag and V. Hasirci (2019). "Development of PEI-RANK siRNA Complex Loaded PLGA Nanocapsules for the Treatment of Osteoporosis." Tissue Eng Part A 25(1-2): 34-43.

Shimer, A. L., F. C. Oner and A. R. Vaccaro (2009). "Spinal reconstruction and bone morphogenetic proteins: open questions." Injury 40 Suppl 3: S32-38.

Shin, J., J. H. Cho, Y. Jin, K. Yang, J. S. Lee, H. J. Park, H. S. Han, J. Lee, H. Jeon, H. Shin and S. W. Cho (2016). "Mussel Adhesion-Inspired Reverse Transfection Platform Enhances Osteogenic Differentiation and Bone Formation of Human Adipose-Derived Stem Cells." Small 12(45): 6266-6278.

Smith, W. C. and R. M. Harland (1992). "Expression cloning of noggin, a new dorsalizing factor localized to the Spemann organizer in Xenopus embryos." Cell 70(5): 829-840.

Stepinski, J., C. Waddell, R. Stolarski, E. Darzynkiewicz and R. E. Rhoads (2001). "Synthesis and properties of mRNAs containing the novel "anti-reverse" cap analogs 7-methyl(3'-O-methyl)GpppG and 7-methyl (3'-deoxy)GpppG." RNA 7(10): 1486-1495. 
Strenkowska, M., J. Kowalska, M. Lukaszewicz, J. Zuberek, W. Su, R. E. Rhoads, E. Darzynkiewicz and J. Jemielity (2010). "Towards mRNA with superior translational activity: synthesis and properties of ARCA tetraphosphates with single phosphorothioate modifications." New J Chem 34(5): 993-1007.

Suen, P. K. and L. Qin (2016). "Sclerostin, an emerging therapeutic target for treating osteoporosis and osteoporotic fracture: A general review." J Orthop Translat 4: 1-13.

Sun, Y., X. Ye, M. Cai, X. Liu, J. Xiao, C. Zhang, Y. Wang, L. Yang, J. Liu, S. Li, C. Kang, B. Zhang, Q. Zhang, Z. Wang, A. Hong and X. Wang (2016). "Osteoblast-Targeting-Peptide Modified Nanoparticle for siRNA/microRNA Delivery." ACS Nano 10(6): 5759-5768.

Suzuki, K., A. Kumanogoh and H. Kikutani (2008). "Semaphorins and their receptors in immune cell interactions." Nat Immunol 9(1): 17-23.

Svedbom, A., E. Hernlund, M. Ivergard, J. Compston, C. Cooper, J. Stenmark, E. V. McCloskey, B. Jonsson, J. A. Kanis and E. U. R. P. O. IOF (2013). "Osteoporosis in the European Union: a compendium of countryspecific reports." Arch Osteoporos 8: 137.

Svitkin, Y. V., Y. M. Cheng, T. Chakraborty, V. Presnyak, M. John and N. Sonenberg (2017). "N1-methylpseudouridine in mRNA enhances translation through elF2alpha-dependent and independent mechanisms by increasing ribosome density." Nucleic Acids Res 45(10): 6023-6036.

Takahashi, K., K. Tanabe, M. Ohnuki, M. Narita, T. Ichisaka, K. Tomoda and S. Yamanaka (2007). "Induction of pluripotent stem cells from adult human fibroblasts by defined factors." Cell 131(5): 861872.

Takahashi, K. and S. Yamanaka (2006). "Induction of pluripotent stem cells from mouse embryonic and adult fibroblast cultures by defined factors." Cell 126(4): 663-676.

Takayama, K., A. Suzuki, T. Manaka, S. Taguchi, Y. Hashimoto, Y. Imai, S. Wakitani and K. Takaoka (2009). "RNA interference for noggin enhances the biological activity of bone morphogenetic proteins in vivo and in vitro." Journal of Bone and Mineral Metabolism 27(4): 402-411.

Teng, S., C. Liu, C. Krettek and M. Jagodzinski (2014). "The application of induced pluripotent stem cells for bone regeneration: current progress and prospects." Tissue Eng Part B Rev 20(4): 328-339. Thess, A., S. Grund, B. L. Mui, M. J. Hope, P. Baumhof, M. Fotin-Mleczek and T. Schlake (2015). "Sequence-engineered mRNA Without Chemical Nucleoside Modifications Enables an Effective Protein Therapy in Large Animals." Mol Ther 23(9): 1456-1464.

Trepotec, Z., M. K. Aneja, J. Geiger, G. Hasenpusch, C. Plank and C. Rudolph (2019). "Maximizing the Translational Yield of mRNA Therapeutics by Minimizing 5'-UTRs." Tissue Eng Part A 25(1-2): 69-79. Triana-Alonso, F. J., M. Dabrowski, J. Wadzack and K. H. Nierhaus (1995). "Self-coded 3'-extension of run-off transcripts produces aberrant products during in vitro transcription with T7 RNA polymerase." J Biol Chem 270(11): 6298-6307.

Uchida, S., K. Kataoka and K. Itaka (2015). "Screening of mRNA Chemical Modification to Maximize Protein Expression with Reduced Immunogenicity." Pharmaceutics 7(3): 137-151.

Urist, M. R. and B. S. Strates (2009). "The classic: Bone morphogenetic protein." Clin Orthop Relat Res 467(12): 3051-3062.

van der Velden, A. W. and A. A. Thomas (1999). "The role of the $5^{\prime}$ untranslated region of an mRNA in translation regulation during development." Int J Biochem Cell Biol 31(1): 87-106.

Wada, T., T. Nakashima, N. Hiroshi and J. M. Penninger (2006). "RANKL-RANK signaling in osteoclastogenesis and bone disease." Trends Mol Med 12(1): 17-25.

Wan, D. C., J. H. Pomerantz, L. J. Brunet, J. B. Kim, Y. F. Chou, B. M. Wu, R. Harland, H. M. Blau and M. T. Longaker (2007). "Noggin suppression enhances in vitro osteogenesis and accelerates in vivo bone formation." J Biol Chem 282(36): 26450-26459.

Wang, C., F. Xiao, Y. Gan, W. Yuan, Z. Zhai, T. Jin, X. Chen and X. Zhang (2018). "Improving Bone Regeneration Using Chordin siRNA Delivered by $\mathrm{pH}$-Responsive and Non-Toxic Polyspermine Imidazole4,5-Imine." Cell Physiol Biochem 46(1): 133-147. 
Wang, C., W. Yuan, F. Xiao, Y. Gan, X. Zhao, Z. Zhai, X. Zhao, C. Zhao, P. Cui, T. Jin, X. Chen and X. Zhang (2017). "Biscarbamate Cross-Linked Low-Molecular-Weight Polyethylenimine for Delivering Anti-chordin siRNA into Human Mesenchymal Stem Cells for Improving Bone Regeneration." Frontiers in Pharmacology 8.

Wang, H., J. Liu, S. Tao, G. Chai, J. Wang, F. Q. Hu and H. Yuan (2015). "Tetracycline-grafted PLGA nanoparticles as bone-targeting drug delivery system." Int J Nanomedicine 10: 5671-5685.

Wang, Y. and D. W. Grainger (2010). "siRNA knock-down of RANK signaling to control osteoclastmediated bone resorption." Pharm Res 27(7): 1273-1284.

Wang, Y., K. K. Tran, H. Shen and D. W. Grainger (2012). "Selective local delivery of RANK siRNA to bone phagocytes using bone augmentation biomaterials." Biomaterials 33(33): 8540-8547.

Warren, L., P. D. Manos, T. Ahfeldt, Y. H. Loh, H. Li, F. Lau, W. Ebina, P. K. Mandal, Z. D. Smith, A. Meissner, G. Q. Daley, A. S. Brack, J. J. Collins, C. Cowan, T. M. Schlaeger and D. J. Rossi (2010). "Highly efficient reprogramming to pluripotency and directed differentiation of human cells with synthetic modified mRNA." Cell Stem Cell 7(5): 618-630.

Wei, C. M., A. Gershowitz and B. Moss (1975). "Methylated nucleotides block 5 ' terminus of HeLa cell messenger RNA." Cell 4(4): 379-386.

Weissman, D., N. Pardi, H. Muramatsu and K. Kariko (2013). "HPLC purification of in vitro transcribed long RNA." Methods Mol Biol 969: 43-54.

Wesselhoeft, R. A., P. S. Kowalski and D. G. Anderson (2018). "Engineering circular RNA for potent and stable translation in eukaryotic cells." Nat Commun 9(1): 2629.

Wesselhoeft, R. A., P. S. Kowalski, F. C. Parker-Hale, Y. Huang, N. Bisaria and D. G. Anderson (2019). "RNA Circularization Diminishes Immunogenicity and Can Extend Translation Duration In Vivo." Mol Cell. Wolff, J. A., R. W. Malone, P. Williams, W. Chong, G. Acsadi, A. Jani and P. L. Felgner (1990). "Direct gene transfer into mouse muscle in vivo." Science 247(4949 Pt 1): 1465-1468.

Wu, X.-B., Y. Li, A. Schneider, W. Yu, G. Rajendren, J. Iqbal, M. Yamamoto, M. Alam, L. J. Brunet, H. C. Blair, M. Zaidi and E. Abe (2003). "Impaired osteoblastic differentiation, reduced bone formation, and severe osteoporosis in noggin-overexpressing mice." Journal of Clinical Investigation 112(6): 924-934. Xiao, G., R. Gopalakrishnan, D. Jiang, E. Reith, M. D. Benson and R. T. Franceschi (2002). "Bone morphogenetic proteins, extracellular matrix, and mitogen-activated protein kinase signaling pathways are required for osteoblast-specific gene expression and differentiation in MC3T3-E1 cells." J Bone Miner Res 17(1): 101-110.

Yang, E., E. van Nimwegen, M. Zavolan, N. Rajewsky, M. Schroeder, M. Magnasco and J. E. Darnell, Jr. (2003). "Decay rates of human mRNAs: correlation with functional characteristics and sequence attributes." Genome Res 13(8): 1863-1872.

Yoshioka, N., E. Gros, H. R. Li, S. Kumar, D. C. Deacon, C. Maron, A. R. Muotri, N. C. Chi, X. D. Fu, B. D. Yu and S. F. Dowdy (2013). "Efficient generation of human iPSCs by a synthetic self-replicative RNA." Cell Stem Cell 13(2): 246-254.

You, Z., D. Saims, S. Chen, Z. Zhang, D. C. Guttridge, K. L. Guan, O. A. MacDougald, A. M. Brown, G. Evan, J. Kitajewski and C. Y. Wang (2002). "Wnt signaling promotes oncogenic transformation by inhibiting CMyc-induced apoptosis." J Cell Biol 157(3): 429-440.

Yu, Y., G. Jin, Y. Xue, D. Wang, X. Liu and J. Sun (2017). "Multifunctions of dual Zn/Mg ion co-implanted titanium on osteogenesis, angiogenesis and bacteria inhibition for dental implants." Acta Biomater 49: 590-603.

Zangi, L., K. O. Lui, A. von Gise, Q. Ma, W. Ebina, L. M. Ptaszek, D. Später, H. Xu, M. Tabebordbar, R. Gorbatov, B. Sena, M. Nahrendorf, D. M. Briscoe, R. A. Li, A. J. Wagers, D. J. Rossi, W. T. Pu and K. R. Chien (2013). "Modified mRNA directs the fate of heart progenitor cells and induces vascular regeneration after myocardial infarction." Nature Biotechnology 31(10): 898-907. 
Zhang, L., G. Yang, B. N. Johnson and X. Jia (2019). "Three-dimensional (3D) printed scaffold and material selection for bone repair." Acta Biomater 84: 16-33.

Zhang, W., R. E. De La Vega, M. J. Coenen, S. A. Muller, C. J. Peniche Silva, M. K. Aneja, C. Plank, M. van Griensven, C. H. Evans and E. R. Balmayor (2018). "An Improved, Chemically Modified RNA Encoding BMP-2 Enhances Osteogenesis In Vitro and In Vivo." Tissue Eng Part A.

Zhang, Y., L. Wei, R. J. Miron, B. Shi and Z. Bian (2015). "Anabolic bone formation via a site-specific bonetargeting delivery system by interfering with semaphorin 4D expression." J Bone Miner Res 30(2): 286296.

Zhang, Y., L. Wei, R. J. Miron, B. Shi and Z. Bian (2016). "Bone scaffolds loaded with siRNA-Semaphorin4d for the treatment of osteoporosis related bone defects." Sci Rep 6: 26925.

Zhang, Y., L. Wei, R. J. Miron, Q. Zhang and Z. Bian (2014). "Prevention of alveolar bone loss in an osteoporotic animal model via interference of semaphorin 4d." J Dent Res 93(11): 1095-1100.

Zheng, L. Z., X. L. Wang, H. J. Cao, S. H. Chen, L. Huang and L. Qin (2016). "Src siRNA prevents corticosteroid-associated osteoporosis in a rabbit model." Bone 83: 190-196.

Zheng, X. and P. C. Bevilacqua (2004). "Activation of the protein kinase PKR by short double-stranded RNAs with single-stranded tails." RNA 10(12): 1934-1945.

Zhuang, Z., S. Yoshizawa-Smith, A. Glowacki, K. Maltos, C. Pacheco, M. Shehabeldin, M. Mulkeen, N. Myers, R. Chong, K. Verdelis, G. P. Garlet, S. Little and C. Sfeir (2018). "Induction of M2 Macrophages Prevents Bone Loss in Murine Periodontitis Models." J Dent Res: 22034518805984.

Zimmerman, L. B., J. M. De Jesus-Escobar and R. M. Harland (1996). "The Spemann organizer signal noggin binds and inactivates bone morphogenetic protein 4." Cell 86(4): 599-606.

Zohra, F. T., E. H. Chowdhury, S. Tada, T. Hoshiba and T. Akaike (2007). "Effective delivery with enhanced translational activity synergistically accelerates mRNA-based transfection." Biochem Biophys Res

Commun 358(1): 373-378. 